\title{
ANÁLISE ECONÔMICA DA CRIAÇÃO DE PEIXES SOB CONDIÇÕES DE RISCO: UM ESTUDO DE CASO DO PACU
}

\author{
EVA CHABALIN
}

Economista

Orientador: Dr. Evaristo Marzabal Neves

Dissertação apresentada à Escola Superior de Agricultura "Luiz de Queiróz", da Univesidade de São Paulo, para a obtenção do título de Mestre em Ciências, Área de Concentração: Economia Aplicada.

PIRACICABA

Estado de São Paulo

Outubro, 1996 


\section{Dados Internacionais de Catalogação na Publicação (CIP) DIVISÃo DE BIBLIOTECA E DOCUMENTAÇÃO - Campus "Luiz de Queiroz"/USP}

\section{Chabalin, Eva}

Análise econômica da criação de peixes sob condiçōes de risco: um estudo de caso do pacu / Eva Chabalin. - - Piracicaba, 1996

$62 \mathrm{p}$.

Dissertação (mestrado) - E Escola Superior de Agricultura Luiz de Queiroz, 1996.

Bibliografia.

1. Pacu - Produção - Análise econômica 2. Piscicultura - Aspecto economico São Paulo (estado) 3. Simulação I. Titulo 


\title{
ANÁLISE ECONÔMICA DA CRIAÇÃO DE PEIXES SOB CONDIÇÕES DE RISCO: UM ESTUDO DE CASO DO PACU
}

\author{
Eva Chabalin
}

Aprovada em 09.12.1996

Comissão Julgadora:

Prof. Dr. Evaristo Marzabal Neves

Prof. Dr. Paulo F. Cidade de Araújo

Prof. Dr. José Eurico Possebon Cyrino

ESALQ/USP

ESALQ/USP

ESALQ/USP

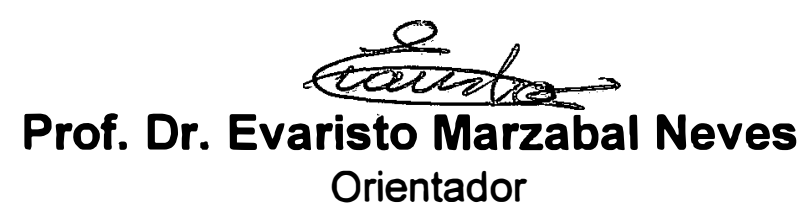


Ao Homem do campo, dedico 


\section{AGRADECIMENTOS}

Ao Professor Dr. Evaristo Marzabal Neves pela valiosa e segura orientação que proporcionou a este trabalho.

Aos Professores Paulo F. Cidade de Araújo e José Eurico Possebon Cyrino da ESALQ/USP e ao Professor José Sávio Colares de Melo do CEPTA/IBAMA, pela leitura crítica e sugestões apresentadas, permitindo o aperfeiçoamento deste trabalho.

Ao Professor José Augusto Ferraz de Lima do CEPTA/IBAMA, pela inestimável colaboração prestada na realização deste e de diversos outros trabalhos.

À CAPES pelo apoio financeiro recebido.

Ao CEPTA/IBAMA pelo apoio técnico-financeiro para a realização deste trabalho. Aos colegas do CEPTA, em particular ao Pesquisador Luis Alberto Gaspar, pela colaboração nos trabalhos de campo.

Ao corpo de professores do Departamento de Economia e Sociologia Rural da ESALQ pelos ensinamentos e formação acadêmica recebidos durante o Curso de Mestrado.

Aos produtores rurais que gentilmente cederam as informações, em especial ao Sr. Nivaldo Rotta e Sr. Ivo Guiotti.

Ao Técnico Armando Ricciardi da UNIDAS, pelo apoio na coleta de dados junto à região do Vale do Ribeira.

Ao Engenheiro Agrônomo Luis Henrique Andia pelo suporte nos trabalhos de informática.

Às Bibliotecárias Maria Anita Pereira da Silva, Elenice Beck Banin Campos (CEPTAIBAMA), Maria Angélica Amador Fanaro, Luciane Cristina Cipriano e Silvia Maria Zinsly (DESR/ESALQ/USP), pela eficiente obtenção da bibliografia necessária.

A todos os funcionários do DESR/ESALQ, especialmente Maielli, Cristiane, Helena, Elenice e Márcia, pela amizade e apoio recebidos.

Sou muito grata a Deus e aos meus pais pela vida e pelos ensinamentos. E ao Gera, pelo companheirismo e compreensão. 


\section{ÍNDICE}

Página

LISTA DE TABELAS...................

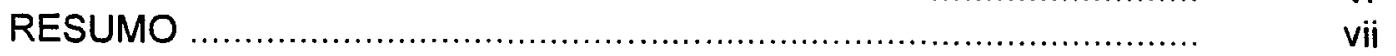

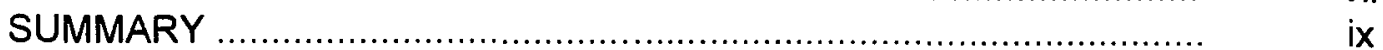

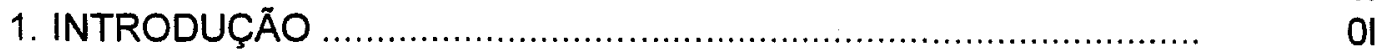

1.1 Considerações gerais ..............................................................

1.2 Importância do estudo ............................................................... 05

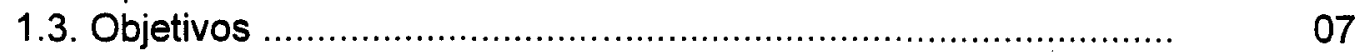

1.4. Organização do estudo ........................................................... 07

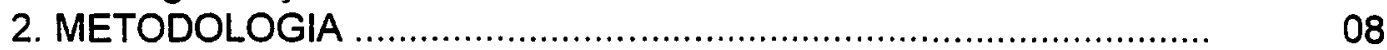

2.1. Procedimentos e critérios para formação do fluxo de caixa ........ 08

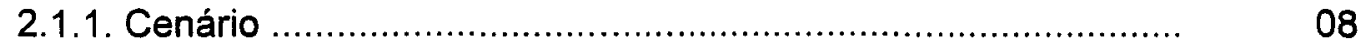

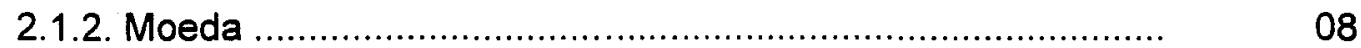

2.1.3. Fluxos de caixa ............................................................. 08

2.1.4. Taxa de Desconto .........................................................

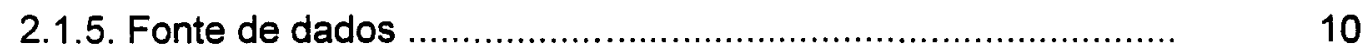

2.2. Análise econômica ........................................................... 10

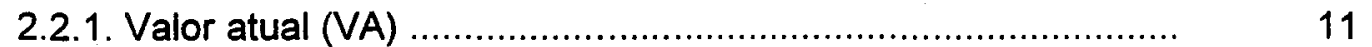

2.2.2. Taxa interna de retorno (TIR) ..............................................

2.2.3. Periodo de recuperação do capital (Payback) ........................ 13

2.2.4. Relação benefício-custo (RBC) ........................................... 13

2.2.5. Custo total atualizado (CTA) ............................................... 13

2.3. Incorporação de medidas de risco ............................................ 14

2.3.1. Uso de medidas de risco ....................................................

2.3.2. Processo de simulação ........................................................... 16

3. RESULTADOS E DISCUSSŌES …..............................................

3.1. Análise determinística ........................................................... 19

3.2. Resultados das simulaçöes ....................................................... 23

4. CONCLUSÃO ................................................................... 31

5. REFEREANCIAS BIBLIOGRÁFICAS .........................................

APÊNDICE 1: Composição dos custos de investimentos e 39 operacionais .....................................................

APÉNDICE 2: Resultados da análise deterministica e 44 de risco para produção de pacu... 


\section{LISTA DE TABELAS}

Página

Tabela 1. Produção da aqüicultura do Brasil, América Latina e mundo (excluindo plantas aquáticas) - periodo 1984/92

Tabela 2. Fluxo de caixa para a criação de pacu na região de Ribeirão Preto, SP

Tabela 3. Fluxo de caixa para a criação de pacu na região do Vale do Ribeira, SP

Tabela 4. Fluxo de caixa para a criação de pacu na região de Presidente Prudente,SP

Tabela 5. Análise Determinística: indicadores de rentabilidade da criação de pacu - região de Ribeirão Preto, SP

Tabela 6. Análise Deterministica: indicadores de rentabilidade da criação de pacu - região do Vale do Ribeira, SP....

Tabela 7. Análise Determinística: indicadores de rentabilidade da criação de pacu - região de Presidente Prudente, SP

Tabela 8. Valores mais prováveis das variáveis consideradas aleatórias, limites superiores e inferiores estabelecidos para a simulação - região de Ribeirão Preto, SP.

Tabela 9. Valores mais prováveis das variáveis consideradas aleatórias, limites superiores e inferiores estabelecidos para a simulação - região do Vale do Ribeira, SP.

Tabela10. Valores mais prováveis das variáveis consideradas aleatórias, limites superiores e inferiores estabelecidos para a simulação - região de Presidente Prudente, SP.

Tabela11. Simulação: valores médios e desvio-padrão dos indicadores econômicos - taxa de desconto de $6 \%$ a.a. - região de Ribeirão Preto, SP.

Tabela12. Simulação: Valores obtidos (máximo e mínimo) para os indicadores econômicos - região de Ribeirão Preto, SP.

Tabela13. Simulação: valores médios e desvio-padrão dos indicadores econômicos - taxa de desconto de $6 \%$ a.a.- regiäo do Vale do Ribeira, SP.

Tabela14. Simulação: valores obtidos (máximo e mínimo) para os indicadores econômicos - região do Vale do Ribeira, SP .......

Tabela15. Simulação: valores médios e desvio-padrão dos indicadores econômicos - taxa de desconto de $6 \%$ a.a.- região de Presidente Prudente, SP

Tabela16. Simulação: valores (máximo e mínimo) obtidos para os indicadores econômicos - região de Presidente Prudente, SP

Tabela17. Resultados econômicos obtidos, para outras atividades pecuárias, através do Método de Monte Carlo. 


\title{
ANÁLISE ECONÔMICA DA CRIAÇÃO DE PEIXES SOB CONDIÇÕES DE RISCO: UM ESTUDO DE CASO DO PACU
}

\author{
Eva Chabalin
}

Orientador: Dr. Evaristo Marzabal Neves

RESUMO

A degradação dos ambientes aquáticos e consequente redução da oferta de pescado vêm despertando o interesse pela aqüicultura como alternativa de investimento.

A dinamização desse processo requer informações técnicoeconômicas para a análise de sua viabilidade. Este estudo determina custo de produção e a rentabilidade econômica da criação de pacu sob condições de risco, considerando a área de 3ha de espelho d'água, para três regiōes do Estado de São Paulo: Ribeirão Preto, Vale do Ribeira e Presidente Prudente.

Para a determinação dos indicadores de rentabilidade em condições de risco utilizou-se a simulação Monte Carlo. Considerou-se como variáveis aleatórias os coeficientes técnicos de sobrevivência, a densidade de estocagem, a conversão alimentar aparente, o peso final do pescado e os preços de alevino, pescado, ração e construção dos viveiros.

Os indicadores econômicos obtidos sinalizam a atratividade do empreendimento apresentando valores próximos para as três regiōes, devido às semelhanças dos sistemas de produção. 
Para a análise determinística, os valores alcançados para as taxas internas de retorno variaram ao redor de $45 \%$, que comparadas às respectivas alternativas do custo do capital para o empreendimento, sugerem a viabilidade econômica da criação.

Com a simulação verificou-se que as regiões estudadas apresentam Taxa Interna de Retorno (TIR) média próxima a $60 \%$, com probabilidade acima de $90 \%$ das TIR's ocorrerem com valores superiores a $20 \%$. O custo total unitário obtido foi de $R \$ 1,64 / \mathrm{kg}, \mathrm{R} \$ 1,57 / \mathrm{kg}$ e $R \$ 1,58 / \mathrm{kg}$ para as regiões de Ribeirão Preto, Vale do Ribeira e Presidente Prudente, respectivamente, indicando que os piscicultores vêm obtendo boa remuneração com a venda do pescado aos preços de $R \$ 2,50 / \mathrm{kg}$ a $R \$$ $3,00 / \mathrm{kg}$, comercializado junto aos pesque-pagues na última safra (1995/96).

Os valores obtidos para a Relação Benefício/Custo (RBC), próximos aos $\mathrm{R} \$ 1,70$ e o tempo de recuperação do capital (Payback) variando ao redor de 2,5 anos, refletem a boa atratividade do investimento. 


\section{ECONOMIC ANALYSIS OF THE FISH REARING UNDER RISK CONDITIONS: A CASE STUDY OF PACU}

Eva Chabalin

Adviser: Dr. Evaristo Marzabal Neves

\section{SUMMARY}

This study determines the production cost and the economic return of pacu rearing in risk conditions, considering a three hectare area of water, in three regions of São Paulo State: Ribeirão Preto, Vale do Ribeira e Presidente Prudente.

For the determination of the indicators under risk conditions was utilized Monte Carlo Simulation. The technical coefficients of survival, feed conversion, stocking density and final weight of fish, and the prices of fingerling, fish, ration and pond construction were considered as random variables.

The economic indicators present similar values for the three regions, due to the likeness in production system.

The internal rates of return (IRR) at about $45 \%$ were obtained form the determnist analysis, when compared with investment opportunity alternatives, suggest the economic viability of rearing.

With the simulation analysis it was found that all regions present internal mean rate-of-return near $60 \%$, with probability above $90 \%$ of IRR to occur with values superior to $20 \%$. The total unitary cost obtained was $R \$ 1.64 / \mathrm{kg}, \mathrm{R} \$ 1.57 / \mathrm{kg}$ and $\mathrm{R} \$ 1.58 / \mathrm{kg}$ for regions of Ribeirão Preto, Vale do Ribeira and Presidente Prudente respectively, and the sales price of fish range from $R \$ 2.50 / \mathrm{kg}$ to $\mathrm{R} \$ 3.00 / \mathrm{kg}$, under the system "fishing and pay" in the last period (1995/96). 
The values obtained for the benefit-cost ratio was $R \$ 1.70$ and the payback period close to 2.5 years, both reflecting an attractive investment. 


\section{INTRODUÇÃO}

\section{1 - Considerações Gerais}

A oferta de pescado no Brasil passou de 526,3 mil toneladas em 1970 para 798,6 mil toneladas em 1989 , com pico de 971,5 mil toneladas em 1985, quando passou a ter sucessivos decréscimos na produção' (Neiva, 1990; IBGE, 1992). Os recursos pesqueiros encontram-se super-explotados, e as expectativas de aumento da produção através das capturas são pouco prováveis, devido principalmente à degradação dos ambientes marinhos e de água-doce (Ferraz de Lima, 1987; Neiva, 1990).

A degradação ambiental e o desperdicio econômico na realização de longas prospecções em capturas, provocaram o interesse pela aqüicultura como alternativa de agroindústria em diversas regiões do mundo (New et al., 1995). A aqüicultura, segundo a FAO (1992), é definida como a criação de organismos aquáticos, em condiçōes controladas, incluindo peixes, moluscos, crustáceos e plantas aquáticas, onde ocorre alguma forma de intervenção do homem no processo de produção.

$\mathrm{Na}$ comparação das caracteristicas mercadológicas para a produção extrativista de pescado e aqüicultura, o processo de produção controlada apresenta importantes vantagens. $A$ aqüicultura apresenta maior eficiência no uso do tempo e dos esforços, e garante oferta constante do produto em quantidade e qualidade, enquanto a produção do ambiente natural é sazonalmente baixa ou não disponivel, além de possibilitar a comercialização em ocasiões mais lucrativas. Estas vantagens possibilitam ao produtor ofertar o pescado proveniente da criação em cativeiro em

\footnotetext{
${ }^{1}$ As estatisticas oficiais de produção da pesca brasileira, encontram-se disponiveis até 1989.
} 
épocas de elevada procura e nas entressafras do ciclo pesqueiro anual, quando a oferta do produto oriundo do ambiente natural é baixa.

Sendo uma atividade largamente controlada, a aqüicultura tem grandes perspectivas de avanços tecnológicos, com a utilização de técnicas de melhoramento genético e manejo alimentar para o aumento da produção, a exemplo das demais espécies de animais domésticos. Os peixes são eficientes convertedores de alimentos, podendo em muitos casos ser criados apenas com alimento natural disponivel no meio (sistema extensivo), ou com alimento resultante de fertilização e mais o alimento suplementar esporádico (semi-intensivo), ou ainda com a utilização de alimentos processados ricos em proteínas e energia (intensivo). Segundo Tacon (1993), 80\% da produção mundial de pescado e camarão, criados em cativeiro, são provenientes de sistemas extensivo e semi-intensivo.

Nesta última década a aqüicultura teve um expressivo crescimento econômico e deve continuar expandindo sua contribuição no suprimento de peixes para a alimentação humana (FAO, 1995). As estatísticas de 1992 mostram que, em nivel mundial, a produção da aqüicultura, incluindo plantas e algas, estava em 19,3 milhões de toneladas, representando mais de $14,0 \%$ da oferta dos recursos aquáticos obtidos da extração, contra os $8,3 \%$ em 1984. Para o ano 2.000, Nash (1987) estimou, a partir da taxa média anual de crescimento, que esta participação na produção mundial de pescado será de aproximadamente $25,0 \%$.

Das 15 milhões de toneladas de pescado produzidas em 1990 pela aqüicultura, $32,5 \%$ foram representados pelos ciprinídeos (carpas), $20,8 \%$ pelas algas e plantas aquáticas, $10,4 \%$ por outros peixes de águadoce, $7,1 \%$ por mexilhões e os demais $29,2 \%$ por ostras, crustáceos, salmões, outros moluscos e outros peixes (FAO, 1992). A produção da aqüicultura da América Latina entre 1984 e 1992, aumentou cerca de 180\%, chegando a 325.000 toneladas. Os maiores produtores sulamericanos são 
Equador (36,0\%), Chile (21,0\%), México (13,0\%) e Brasil (9,1\%). A evolução da produção da aqüicultura encontra-se ilustrada na Tabela I.

Tabela 1 - Produção da aqüicultura do Brasil, América Latina e Mundo (excluindo plantas aquáticas) - periodo 1984/92 - em toneladas

\begin{tabular}{cccc}
\hline Ano & Brasil & América Latina & Mundial \\
\hline 1984 & 10.700 & 117.503 & 6.911 .860 \\
1985 & 10.873 & 122.992 & 7.700 .678 \\
1986 & 10.980 & 120.825 & 8.776 .802 \\
1987 & 13.130 & 181.303 & 10.123 .027 \\
1988 & 15.530 & 201.554 & 11.176 .637 \\
1989 & 18.130 & 211.681 & 11.448 .061 \\
1990 & 20.430 & 241.911 & 12.080 .167 \\
1991 & 23.300 & 281.335 & 12.756 .256 \\
1992 & 29.700 & 325.228 & 13.899 .788 \\
\hline
\end{tabular}

Fonte: FAO. Review of the state of wold fishery resources: aquaculture. FAO Fish. Circ., n. 886, 127 p. 1995.

Em termos de valores monetários, a produção da América Latina em 1992 correspondeu a US\$ 1,291 bilhões, dos quais 42,0\% atribuidos ao Equador, $21,0 \%$ ao Chile, $10,0 \%$ ao Brasil e $9,0 \%$ à Colômbia.

Até a década de 70 a aqüicultura no Brasil era baseada na explotação de espécies exóticas como carpa, tilápia e salmonideos (Azevedo, 1972; FAO, 1974). A partir dos anos 80, as investigações concentraram-se nas espécies nacionais, com principal esforço sobre a criação dos serrasalmineos pacu Piaractus mesopotamicus, tambaqui Colossoma macropomum, pirapitinga $P$. brachypomum e seus hibridos. 
O pacu foi escolhido para este estudo porque, juntamente com - tambaqui, vem concentrando o maior esforço de pesquisa em aqüicultura, como forma de assegurar a continuidade da oferta dessas espécies, (Hernandez, 1989). De grande aceitação no mercado, o pacu é uma espécie indígena, da Bacia do Prata, com maior concentração na Bacia do Alto Paraguai. Trata-se de um peixe rústico e de hábito alimentar onivoro, e na natureza alimenta-se mais freqüentemente de folhas, frutos, sementes, moluscos e crustáceos, tornando-se facilmente adaptável à criação em cativeiro (Castagnolli \& Zuim, 1985; Chabalin et al., 1988; Paula et al., 1989; Ferraz de Lima et al., 1992). Dentre os serrasalmíneos, o pacu é o que apresenta maior tolerância às temperaturas abaixo de $20^{\circ} \mathrm{C}$ das regiões Sudeste e Sul do País (Saint-Paul, 1987).

O estágio do conhecimento técnico-científico sobre a criação das espécies do gênero Colossoma e Piaractus já viabiliza a criação em nivel de produtores rurais em todo o País. Em 1989 foram registradas 583 publicações técnico-científicas referentes à bioecologia, reprodução, manejo, patologia e alimentação envolvendo essas espécies, porém sem avaliação econômica consistente ( Hernandez, 1989).

A criação do pacu já se faz presente em muitas propriedades rurais do Estado de São Paulo. Atualmente, o principal canal de escoamento da produção são os pesque-pagues. Estes se constituem em um sistema de comercialização alternativo de pescado, realizado através de pescarias esportivas em viveiros contendo peixes jovens e adultos, cuja remuneração geralmente ocorre pelo pagamento de uma taxa de acesso às pescarias e/ou pagamento pelo quilograma de pescado capturado.

Este sistema foi adotado primeiramente no Estado de São Paulo, a fim de facilitar o escoamento da produção dos piscicultores, que passaram a ter a oportunidade de colocação total ou parcial dos peixes localmente, sem a necessidade de beneficiamento do produto e sem 
exigências de oferta constante. Para o consumidor final, os pesque-pagues tornaram-se uma alternativa de lazer baixo custo, em comparação às oportunidades de pescarias em rios piscosos de outras regiões. Além de propiciar o hábito de consumo de pescado com tamanhos inferiores aos normalmente comercializados, os pesque-pagues vêm estimulando o desenvolvimento de outras atividades do setor aquicola, como a produção de alevinos, criação de jovens para engorda, fabricação de ração e equipamentos para manuseio, transporte e produção.

\section{2 - Importância do Estudo}

A aqüicultura é vista por Secretan \& Nash (1989) como uma indústria de alto risco, detendo significativas oportunidades para um rápido retorno sobre os investimentos.

Embora exista um grande número de trabalhos sobre a criação de pacu em nível nacional, a literatura referente à economicidade da criação dessa espécie em cativeiro é ainda escassa. O produtor rural ainda não dispõe de informações sobre o planejamento financeiro da criação, que the permitam decidir sobre investir na atividade, e conhecer o nível de segurança dos retornos. A falta de estudos nessa área dificulta o desenvolvimento efetivo da aqüicultura, limitando a determinação do nivel de risco envolvido ao se tratar os coeficientes técnicos e preços dos fatores e produto com comportamento aleatório, e não constante.

$A$ análise da literatura existente sobre economia da produção em aqüicultura, revela a ausência de incorporação de medidas de risco no processo de decisão. A exceção para o caso brasileiro é o trabalho de Amaral (1989), que analisa o risco na criação de pós-larvas do camarão de água-doce Macrobrachium rosenbergii e, o trabalho de Martin et al. (1995), 
onde analisam variações pontuais de preços de venda de várias espécies de peixes criadas e intensidades de produção. Outros estudos, apresentam análises do tipo "cross section", cujos cenários não consideram as possibilidades de existência de resultados diferentes daquele obtido, além de não considerarem o valor da moeda no tempo, e de utilizarem diferentes itens e métodos de cálculos de custos, não permitindo, muitas vezes a comparação das informações (Chabalin \& Ferraz de Lima, 1988; Chabalin et al., 1989; Torloni et al., 1991; Chabalin et al., 1992; Ferreira Junior et al., 1994; Leboute et al., 1994; Portz et al., 1994).

Muitas avaliações de investimento da agropecuária enfocam não apenas um valor do custo de produção, mas uma distribuição de freqüência do mesmo, como forma de tratamento do risco (Contador, 1981; Cruz, 1984; Neves, 1984; Neves \& Azevedo Filho, 1985; Sá, 1985; Arruda, 1986; Neves \& Couto, 1987; Noronha, 1987; Azevedo Filho, 1988; Latapia, 1988; Amaral, 1989; Brunelli, 1990). Segundo Noronha (1987), dentre as técnicas de análise de risco que utilizam probabilidade, os modelos de simulação devem incorporar as condições de risco, de forma adequada do ponto de vista teórico e exequivel sem maiores dificuldades práticas.

O presente estudo pretende inserir esta linha metodológica na análise de riscos, tratando a criação de pacu como um investimento sujeito a riscos e incertezas na produção. Esse enfoque é de importância na geração de informações que possibilitem responder às questões dos produtores rurais, não somente em relação à rentabilidade da criação de pacu, mas também com relação às chances de obtenção de retornos acima de determinado nivel. O propósito final deste trabalho é auxiliar os investidores no processo de decisão sobre a aqüicultura, estabelecendo-a como mais uma alternativa de renda da propriedade, contribuindo para a continuidade da oferta do pescado produzido em cativeiro. 


\section{3 - Objetivos}

O objetivo geral deste trabalho é desenvolver um modelo conceitual de análise econômica da criação do pacu, incluindo o fator risco, visando auxiliar o processo de tomada de decisão dos produtores.

Objetivos especificos: estimar os custos de produção (engorda) de pacu, usando como modelo os produtores do Estado de São Paulo; analisar os indicadores econômicos obtidos através do processo de simulação pelo Método de Monte Carlo; e, discutir a rentabilidade econômica da criação de pacu.

\section{4 - Organização do Estudo}

Este estudo está dividido em quatro seções. A primeira discute a importância da avaliação econômica na criação de pacu; a segunda, apresenta uma exposição dos critérios para determinação dos indicadores econômicos, seguido da revisão dos procedimentos para incorporação de medidas de risco; a terceira apresenta e discute os resultados das análises deterministica e de risco; e, finalmente, na quarta seção, são apresentadas as principais conclusões obtidas da rentabilidade da criação. 


\section{METODOLOGIA}

\section{1 - Procedimentos e Critérios para a Formação dos Fluxos de Caixa}

\subsection{1 - Cenário}

O cenário considerado neste estudo foi o do ciclo de produção anual, com povoamento dos viveiros no início do primeiro trimestre do ano, quando ocorre maior disponibilidade de alevinos da espécie em estudo.

O horizonte de planejamento do investimento, relacionado à vida econômica do projeto, é de 20 anos. As benfeitorias e equipamentos com vida útil superior ao horizonte assumido para o projeto serão revertidos em receitas no ano de liquidação do projeto. Os investimentos ocorrerão no primeiro ano (ou ano zero) e as receitas terão início a partir do primeiro ano.

\subsection{2 - Moeda}

Considerando a atual estabilidade econômica do Brasil, a moeda adotada foi o Real. O valor do dólar americano é de aproximadamente $\mathrm{R} \$ 1,00$ para a compra e venda (julho/1996).

\subsection{3 - Fluxos de Caixa}

Fluxos de caixa são valores monetários que refletem as entradas e saídas de recursos e produtos por unidade de tempo que formam uma proposta de investimento (Noronha, 1987). Nos fluxos de entrada são considerados os valores da venda do pescado ao fim de cada ciclo de produção e os valores residuais dos bens de capital, estabelecimentos em $10 \%$ do valor do bem novo (Neves, 1984).

Para os fluxos de saída foram registradas as despesas de investimento e as despesas operacionais. As despesas básicas de investimento compreenderam a construção dos viveiros e instalação de um 
depósito tipo galpão, aquisição de veículo, equipamentos e rede de arrasto. Para o depósito, foi considerada a área de $16 \mathrm{~m}^{2}$ necessária para a guarda de ração, petrechos de pesca e materiais diversos. Em termos de equipamentos, foi admitido a necessidade de balanças para até $300 \mathrm{~kg}$ e $2 \mathrm{~kg}$, potenciômetro, oximetro e aeradores. Os preços foram obtidos junto a lojas especializadas do ramo. Para os custos de construção dos viveiros, foram levantadas informações junto aos produtores rurais e especialistas na área, visando obter um intervalo de custo, conforme a demanda para implantação em solos com topografia variada e utilização de maquinaria diversificada para escavação e compactação.

$\mathrm{Na}$ composição das despesas operacionais, foram consideradas aquelas mais usuais para a criação de peixes: aquisição de alevinos, rações, fertilizantes, calcário, mão-de-obra, encargos sociais, assistência técnica, energia elétrica, aluguel da terra e despesas diversas. O número de alevinos para povoamento dos viveiros foi determinado através da taxa de sobrevivência obtida pelos produtores. A quantidade de ração foi estabelecida em função da conversão alimentar aparente. Em relação ao custo de mão-de-obra (salário mais encargos sociais), foi utilizado o valor médio obtido através da pesquisa, admitindo-se $R \$ 200,00$ para um encarregado da piscicultura, e R\$250,00 para um guarda noturno. No custo do aluguel da terra foi considerando $3 \%$ do valor da terra (Neves, 1984). Para as despesas diversas foi atribuida uma taxa de $3 \%$ sobre o custo operacional. Em relação a fertilização e correção de $\mathrm{pH}$, foram adotadas as quantidades recomendadas na literatura (Sobue et al., 1977; Sobue, 1980; Castagnolli et al., 1982a e b), as quais consistem geralmente em adubação inicial com $3 \mathrm{t}$ de adubo bovino/ha seguidas de adubações mensais com 2t/ha; e para o calcário, 3t/ha inicial, seguido de 1 t/ha mensal.

A diferença entre os fluxos de entrada e saída, chamada de fluxo líquido, foi calculada para aplicação da técnica de desconto. 


\subsection{4 - Taxa de Desconto}

Do ponto de vista econômico, Noronha (1987) refere-se ao custo de oportunidade do capital como sendo dado pela taxa que represente seu uso alternativo, e uma medida normalmente adotada, é a taxa de juros do mercado financeiro. Para este estudo foram considerandas como taxas mínimas de atratividade, as taxas de desconto de $6 \%, 9 \%$ e $12 \%$ ao ano (correspondendo respectivamente a taxa de juros da caderneta de poupança, valor intermediário e taxa de juros do mercado internacional).

\subsection{5 - Fonte de Dados}

Os dados técnicos e econômicos de criação foram obtidos através de pesquisa de campo, via entrevistas diretas com os piscicultores de três regiōes do Estado de São Paulo: Vale do Ribeira (compreendendo 18 piscicultores junto aos municípios de Pariquera-Açu, Juquiá, Registro, Cananéia e Miracatu); Presidente Prudente (10 piscicultores de Bauru, Cândido Mota, Presidente Prudente, Rancharia, Anastácio, João Ramalho e Avaí); e Ribeirão Preto (10 piscicultores de Pirassununga, Mococa, Ribeirão Preto, Orlândia, Cajuru, Descalvado, Rio Claro e São Carlos).

Os dados de campo foram respaldados e/ou complementados com as informações técnico-cientificas disponiveis na literatura, e também através de consultas a técnicos da área.

\section{2 - Análise Econômica}

A análise econômica de projetos se constitui em uma ferramenta de avaliação técnica e econômica que possui várias finalidades, dentre as quais a de estabelecer um instrumento auxiliar na tomada de decisão de investimento, na avaliação de novas tecnologias, na avaliação de propostas de financiamento e acesso a programas de crédito rural 
(Noronha, 1987). No tratamento da análise de risco, primeiramente deve-se considerar a elaboração de indicadores econômicos do projeto, calculados a partir de seu fluxo de benefícios e custos.

Neste estudo foram utilizados os critérios ou métodos mais empregados na análise econômica de projetos, os quais consideram a dimensão tempo de valores monetários, conforme citados em Faro (1971), Contador (1981), Noronha (1987) e Azevedo Filho (1988). Estes critérios são: o período necessário para recuperação do capital investido ("payback"); valor atual do projeto (VA); taxa de juros que iguala o valor atual dos retornos futuros ao custo do investimento no presente (TIR); a relação benefício-custo ( $R B C$ ); e custo total atualizado (CTA).

Noronha (1987) ressalta que a maioria dos métodos de análise são auxiliares, devendo ser observados em conjunto, uma vez que todos apresentam limitações em diversos graus. A definição dos critérios é apresentada a seguir, de maneira suscinta ${ }^{2}$.

\subsection{1 - Valor Atual (VA)}

Corresponde à soma algébrica dos valores do fluxo de um projeto, atualizados à taxa adequada de desconto. Este critério é definido por:

$\mathrm{VA}=\sum_{i=0}^{n} \frac{\left(B_{i}-C_{i}\right)}{(1+j)^{i}}$

onde $B_{i}$ é o fluxo de benefícios em unidade monetária no ano $i ; C_{i}$ o fluxo dos custos em unidade monetária no ano $\mathrm{i}$; j é a taxa de juros considerada; e $n$ é a vida útil do projeto.

2 Mais detalhes das características dos critérios podem ser encontrados em Faro (1971), Contador (1981), Noronha (1987) e Azevedo Filho (1988). 
O projeto é julgado economicamente viável quando apresentar um VA positivo. Para uma dada taxa de juros considerada, ao se obter um VA positivo, siginifica que o valor atribuido no presente às receitas futuras será superior ao valor do investimento inicial necessário para a implantação do projeto e demais despesas efetuadas.

\subsection{2 - Taxa Interna de Retorno (TIR)}

É a taxa de juros que iguala a zero o valor atual ou presente líquido do projeto. $A$ TIR $=j$, tal que

$\sum_{i=1}^{n} \frac{\left(B_{i}-C_{i}\right)}{(1+j)^{i}}=0$

onde $\mathrm{Bi}$ é o benefício do projeto em unidades monetárias no ano i; $\mathrm{Ci}$ é o custo em unidades monetárias no ano $\mathrm{i}$; $\mathrm{j}$ é a taxa de retorno; e n é a vida útil do projeto.

É um dos indicadores mais utilizados. Um projeto será viável se a TIR for igual ou superior ao custo de oportunidade dos recursos para a sua implantação. A sua grande vantagem é que prescinde de informações externas ao projeto, sendo necessário apenas ter o perfil do projeto e noção da taxa de juros ou do custo de oportunidade do capital.

Dentre as desvantagens encontradas para este critério, tem-se a insensibilidade a escalas de projetos $e$ aplicação restrita a projetos convencionais (uma única mudança de sinal na seqüência fluxos de caixa). 


\subsection{3 - Período de Recuperação do Capital ("Payback")}

Também chamado de "payback" econômico (PBE).

$\mathrm{PBE}=\mathrm{K}$, tal que $\quad \sum_{i=0}^{k} \frac{F_{i}}{(1+j)^{i}} \geq 0 \quad$ e $\quad \sum_{i=0}^{k-1} \frac{F_{i}}{(1+j)^{i}}<0$

onde $F_{i}$ é o fluxo líquido de caixa do projeto no ano $i$; e j é a taxa de desconto relevante para a empresa.

Trata-se também de um indicador muito utilizado, principalmente pelo investidor privado. Quanto menor o PBE, tanto melhor é o projeto. Sua análise também fornece uma idéia de liquidez e segurança dos projetos.

\subsection{4 - Relação Benefício-Custo (RBC)}

Consiste na relação entre o valor atual dos benefícios e o valor atual dos custos, sendo definida como

$\mathrm{RBC}=\frac{\sum_{i=0}^{n} B_{i} /(1+j)^{i}}{\sum_{i=0}^{n} C_{i} /(1+j)^{i}}$

onde $\mathrm{Bi}$ é o benefício em unidades monetárias no ano $\mathrm{i}$; $\mathrm{Ci}$ é o custo do projeto em unidades monetárias no ano $\mathrm{i}$; j é a taxa de desconto relevante para a empresa; e $n$ é a vida útil do projeto.

Para o projeto ser viável a relação $\mathrm{B} / \mathrm{C}$ tem de ser maior que 1. Quanto maior o resultado, mais atraente torna-se o projeto.

\subsection{5 - Custo Total Atualizado - CTA}

Também chamado de valor presente dos investimentos, é representado por 
$\mathrm{CTA}=\sum_{i=0}^{n} \frac{C_{i}}{(1+j)^{i}}$

onde $\mathrm{Ci}$ é o custo do projeto em unidades monetárias no ano i; jé a taxa de desconto relevante para a empresa; e n é a vida útil do projeto.

Este indicador é tido como auxiliar na análise econômica e sua maior utilidade é medir a escala do projeto.

De acordo com Azevedo Filho (1988, p. 9), "não existe nenhum método que possibilite conhecer ex-ante os valores exatos de todas as informações utilizadas para a geração do fluxo de caixa. Contudo, a técnica de simulação e alguns principios de decisão em condições de risco podem fornecer alguns subsidios úteis para a incorporação explícita da incerteza no processo de avaliação de projetos".

\section{3 - Incorporação de Medidas de Risco}

\subsection{1 - Uso de Medidas de Risco}

As condições de risco, em geral, aparecem quando existe a probabilidade de ocorrer um resultado diferente daquele que era esperado (Contador, 1981). Nas avaliações econômicas, devem ser consideradas as probabilidades de resultados diferentes, levando-se em conta o risco aleatório envolvido, para servir como indicador auxiliar na tomada de decisão, respaldado por uma margem de segurança.

A teoria de decisão de Bernoulli, citado por Contini et al. (1984), incorpora o risco com base em probabilidades subjetivas do tomador de decisão a respeito da ocorrência de eventos incertos e nas preferências pessoais pelas conseqüências potenciais destes eventos. A partir dessa teoria surgiu o modelo Média-Variância desenvolvido por Markowitz, Tobin e Feldstein, onde é pressuposto que o tomador de decisão 
escolhe a alternativa que apresentar menor variância para uma mesma média, ou a maior média para um nível de variância.

A existência de uma relação estável e empiricamente comprovável para o caso brasileiro entre retorno esperado e risco, foi observada por Contador (1975) . A dispersão de retorno observada junto a média de um ramo de atividade é útil na indicação aproximada do nivel de risco naquela atividade. $O$ autor sugere que atividades com desvios padrão mais elevados, necessitam de retornos médios mais elevados para atrair o interesse dos investidores.

$\mathrm{Na}$ administração da empresa rural, os riscos são classificados como diretos e indiretos. Risco indireto é tido como aquele sobre o qual o produtor tem pouco ou nenhum controle, como por exemplo, as políticas econômicas governamentais e as alterações nas condições climáticas. Já os riscos diretos são considerados de maior importância nas análises de projetos, representando aqueles que podem ser atribuidos a fatores sujeitos ao controle, como densidade de animais em uma área, uso de defensivos agricolas de elevada toxicidade, entre outros (Noronha, 1987)

Dos riscos diretos na aqüicultura, Shang (1990) menciona: a) a má administração da água resultando em baixas taxas de crescimento e elevada mortalidade; b) manejo inadequado de alevinos; c) utilização de alimentação inadequada e/ou com baixos níveis protéicos; d) manejo inadequado nas despescas; e e) alterações nos preços de insumos e produtos.

Entre outras maneiras de introduzir o risco na tomada de decisão ${ }^{3}$, a literatura apresenta:

\footnotetext{
${ }^{3}$ Mais detalhes podem ser encontrados em Contador (1981)
} 
a) critério do Payback - no qual, quanto menor o payback do projeto, mais rápida a recuperação dos investimentos e, portanto, menos sujeito às incertezas e flutuações futuras;

b) análise de sensibilidade - método de simulação que consiste em variar numa certa faixa as estimativas dos parâmetros mais sujeitos a incerteza, e observar o resultado da rentabilidade do projeto; e

c) prêmio para rísco na taxa de desconto - para atividades mais sujeitas a risco, oferecer taxa média de retorno esperado mais elevada do que outras atividades.

\subsection{2 - Processo de Simulação}

Uma das formas de considerar risco na tomada de decisões é fazer variar, numa faixa, as estimativas daqueles parâmetros mais sujeitos a incertezas e observar o que acontece com a rentabilidade do projeto (Contador, 1981). Este processo é conhecido como análise de sensibilidade,e ao fazê-lo, é recomendado modificar uma variável de cada vez, pressupondo que cada variável afeta o resultado do projeto, independentemente das demais (Noronha, 1987).

No presente estudo foi utilizado o Método de Monte Carlo, o qual possibilita a simulação de variáveis selecionadas do projeto, incluindo os indicadores econômicos e a probabilidade dessas váriáveis assumirem valores diferentes dos limites estabelecidos. Para a análise de risco, foram utilizados os valores aproximados dos resultados obtidos na análise deterministica, como valores limites.

Neves (1984), Noronha (1987) e Azevedo Filho (1988) citam que o Método de Monte Carlo foi proposto originalmente por Hertz (1964) ${ }^{4}$,

\footnotetext{
4 - Hertz, O.B. Risk analysis in capital investiment. Harvard Business Review, Harvard, 42(1): 95-106, jan/feb. 1964.
} 
sendo posteriormente ampliado para a análise de projetos do Banco Mundial. A seqüência de cálculos deste método é a seguinte:

1) - identificação da distribuição de probabilidade de cada uma das variáveis relevantes do fluxo de caixa do projeto;

2) - seleção, ao acaso, de um valor de cada variável, a partir de sua distribuição de probabilidade;

3) - cálculo do valor do indicador de escolha, toda vez que for feito o sorteio mencionado no passo anterior, criando assim um novo "projeto"; e

4) - repetição do processo até a obtenção da confirmação adequada da distribuição de freqüência do indicador de escolha, ou até obter uma idéia aproximada do formato da distribuição. A partir da distribuição torna-se possivel verificar a probabilidade de sucesso ou fracasso do projeto.

Uma boa estimativa das distribuições de probabilidade dos indicadores econômicos está associada à melhor estimativa possivel do fluxo de caixa. Por esse processo ser muito subjetivo, devido a dependência do nivel de informação angariada pelo analista, em relação às variáveis relevantes, torna-se necessária a obtenção das melhores estimativas possiveis.

Para a simulação dos dados foi utilizado o aplicativo desenvolvido por Azevedo Filho (1988), denominado ALEAXPRJ - Sistema para Simulação e Análise de Projetos Envolvendo Risco, o qual considera a utilização de técnicas associadas à simulação Monte Carlo, e dispõe de recursos que permitem representar qualquer situação usual, minimizando tempo e custo na análise dos resultados.

As variáveis consideradas de relevância para o processo de simulação foram selecionadas de acordo com a sua influência e/ou maior participação no custo operacional de produção. Para este estudo, as 
variáveis correspondem aos coeficientes técnicos de criação: sobrevivência, densidade de estocagem, conversão alimentar aparente, peso médio final dos peixes; aos preços de aquisição de alevinos (peixes com aproximadamente 40 dias de idade) e de comercialização do pescado, e preço de aquisição de ração.

Outra variável de relevância são os custos de implantação dos viveiros de engorda, devido terem na prática uma variabilidade muito grande, principalmente em função da topografia do terreno e o tipo de maquinaria utilizada na escavação e compactação dos viveiros.

Os valores máximo, modal e mínimo, das variáveis consideradas aleatórias, são obtidos através de pesquisa junto a produtores, técnicos e pesquisadores, assim como na literatura disponivel, de maneira que melhor correspondam à sua distribuição. Os valores modais da distribuição triangular e uniforme são utilizados na avaliação deterministica. 


\section{RESULTADOS E DISCUSSÕES}

Para as três regiōes em estudo, foi observado que a piscicultura é conduzida como atividade secundária na grande maioria das propriedades. O tamanho modal das pisciculturas foi de 3,0 hectares (ha) de espelho d'água em todas as regiōes. $O$ tamanho minimo observado na região de Ribeirão Preto foi de 0,2 ha e o máximo de 8 ,0ha; para a região de Presidente Prudente foi de 1,7ha o mínimo e 7,0ha o máximo; e, para a região do Vale do Ribeira os tamanhos minimo e máximo foram de 1, 0ha e 1,6 ha, respectivamente. Neste estudo foi considerado o tamanho modal de 3,0ha de espelho d'água, e de 10,0ha de área total para as benfeitorias consideradas.

O montante de investimento para implantação de uma piscicultura desse porte apresenta-se de igual valor nas três regiões em estudo. O custo total deste item no ano zero (ano de implantação do projeto) é de $R \$ 81.170,00$, à valores de julho/1996. O detalhamento dos investimentos, juntamente com os itens, quantidades e valores monetários que compõem o custo operacional anual da criação/engorda de pacu, encontra-se no Apêndice 1.

\section{1 - Análise Deterministica}

Os fluxos de caixa obtidos para as regiões em estudo encontram-se ilustrados nas Tabelas 2 a 4. 
Tabela 2 - Fluxo de caixa para a criação de pacu na Região de Ribeirão Preto, SP - em R $\$ 1,00$

\begin{tabular}{lccccc}
\hline & \multicolumn{5}{c}{ Ano } \\
\cline { 2 - 6 } & 0 & 1 a 9 & 10 & 11 a 19 & 20 \\
\hline A - Entradas & & 84.000 & 84.000 & 84.000 & 84.000 \\
- Receita Bruta & - & - & - & - & 370 \\
- Valor Residual & - & & & & \\
B - Saídas & & - & 13.400 & - & - \\
- Investimentos & 81.170 & 46.959 & 46.959 & 46.959 & 46.959 \\
- Custo Operacional & - & & & & \\
C - Fluxo Liquido & & & & & \\
Diferencial (A-B) & $(81.170)$ & 37.041 & 23.641 & 37.041 & 37.411 \\
& & & & & \\
\hline
\end{tabular}

Tabela 3 - Fluxo de caixa para a criação de pacu na Região do Vale do Ribeira, SP - em R\$ 1,00

\begin{tabular}{lccccc}
\hline \multicolumn{1}{c}{ Discriminação } & \multicolumn{5}{c}{ Ano } \\
\cline { 2 - 6 } & 0 & 1 a 9 & 10 & 11 a 19 & 20 \\
\hline A - Entradas & & 84.000 & 84.000 & 84.000 & 84.000 \\
- Receita Bruta & - & - & - & - & 370 \\
- Valor Residual & - & & & & \\
B - Saídas & & - & 13.400 & - & - \\
- Investimentos & 81.170 & 45.959 & 45.959 & 45.959 & 45.959 \\
- Custo Operacional & - & & & & \\
C - Fluxo Líquido & & & & & \\
$\quad$ Diferencial (A-B) & $(81.170)$ & 38.041 & 24.641 & 38.041 & 38.411 \\
& & & & & \\
\hline
\end{tabular}


Tabela 4 - Fluxo de caixa para a criação de pacu na Região de Presidente Prudente, SP - em R\$1,00

\begin{tabular}{|c|c|c|c|c|c|}
\hline \multirow[t]{2}{*}{ Discriminação } & \multicolumn{5}{|c|}{ Ano } \\
\hline & 0 & 1 a 9 & 10 & 11 a 19 & 20 \\
\hline \multicolumn{6}{|l|}{ A - Entradas } \\
\hline - Receita Bruta & - & 84.000 & 84.000 & 84.000 & 84.000 \\
\hline - Valor Residual & - & - & - & - & 370 \\
\hline \multicolumn{6}{|l|}{ B - Saídas } \\
\hline - Investimentos & 81.170 & - & 13.400 & - & - \\
\hline -Custo Operacional & - & 45.773 & 45.773 & 45.773 & 45.773 \\
\hline \multicolumn{6}{|l|}{ C - Fluxo Líquido } \\
\hline Diferencial $(A-B)$ & $(81.170)$ & 38.227 & 24.827 & 38.227 & 38.597 \\
\hline
\end{tabular}

Foi determinada a Taxa Interna de Retorno (TIR) a partir dos fluxos líquidos de caixa, e todas as pisciculturas das regiōes analisadas se enquadram nos chamados Projetos Convencionais, cujos fluxos de caixa apresentam uma única mudança de sinal, apresentando portanto, segundo Faro (1971), uma única TIR. As Tabelas 5 a 7 apresentam os valores encontrados para os indicadores econômicos em condiçōes deterministica. Nestas tabelas, as legendas apresentadas na forma simplificada significam: Valor Atual (VA), Taxa Interna de Retorno (TIR), Relação Benefício/Custo (RBC), Payback Simples (PBS), Payback Econômico (PBE) e Custo Total Atualizado (CTA). 
Tabela 5 - Análise Determinística: indicadores de rentabilidade da criação de pacu - região de Ribeirão Preto, SP

\begin{tabular}{lccc}
\hline \multirow{2}{*}{ Indicador } & \multicolumn{3}{c}{ Taxa de Desconto (\%) } \\
\cline { 2 - 4 } & 6 & 9 & 12 \\
\hline VA (R\$) & $338.735,78$ & $252.748,48$ & $192.032,68$ \\
TIR (\%) & 45,43 & 45,43 & 45,43 \\
RBC & 1,54 & 1,49 & 1,44 \\
PBS (periodos) & 3,00 & 3,00 & 3,00 \\
PBE (periodos) & 3,00 & 3,00 & 3,00 \\
CTA (R\$) & $624.737,60$ & $514.049,36$ & $435.400,58$ \\
\end{tabular}

Tabela 6 - Análise Deterministica: indicadores de rentabilidade da criação de pacu - região do Vale do Ribeira, SP

\begin{tabular}{lccc}
\hline \multirow{2}{*}{ Indicador } & \multicolumn{3}{c}{ Taxa de Desconto (\%) } \\
\cline { 2 - 4 } & 6 & 9 & 12 \\
\hline VA (R\$) & $350.263,05$ & $261.922,67$ & $199.539,47$ \\
TIR (\%) & 46,69 & 46,69 & 46,69 \\
RBC & 1,57 & 1,52 & 1,47 \\
PBS (períodos) & 3,00 & 3,00 & 3,00 \\
PBE (períodos) & 3,00 & 3,00 & 3,00 \\
CTA (R\$) & $613.210,33$ & $504.875,17$ & $427.893,79$ \\
& & & \\
\hline
\end{tabular}

Tabela 7 - Análise Determinística: indicadores de rentabilidade da criação de pacu - região de Presidente Prudente, SP

\begin{tabular}{lccc}
\hline \multirow{2}{*}{ Indicador } & \multicolumn{3}{c}{ Taxa de Desconto (\%) } \\
\cline { 2 - 4 } & 6 & municipios 9 & 12 \\
\hline VA (R\$) & $352.465,28$ & 263.67535 & $200.973,61$ \\
TIR (\%) & 46,92 & 46,92 & 46,92 \\
RBC & 1,58 & 1,52 & 1,47 \\
PBS (periodos) & 3,00 & 3,00 & 3,00 \\
PBE (periodos) & 3,00 & 3,00 & 3,00 \\
CTA (R\$) & $611.008,11$ & $503.122,49$ & $426.459,66$ \\
\hline
\end{tabular}


As Taxas Internas de Retorno obtidas foram $45,43 \%, 46,69 \%$ e $46,92 \%$ para as regiões de Ribeirão Preto, Vale do Ribeira e Presidente Prudente, respectivamente. Essas taxas representam a remuneração do saldo disponível em cada ano, já descontados o capital inicial na análise determinística, não sendo influenciadas pelas taxas de desconto utilizadas.

Verifica-se que, mesmo alterando a taxa de desconto de $6 \%$, $9 \%$ e $12 \%$, a atividade continua sendo economicamente viável para as três regiōes, conforme mostram os indicadores econômicos. A Relação Beneficio/Custo (RBC) apresenta-se acima de 1 e o periodo de recuperação de capital inicial ocorre em três anos. Observa-se também, pelos resultados, que não houve muita diferença entre as regiões.

\section{2 - Resultados das Simulações}

As variáveis consideradas aleatórias, assim como os valores mais prováveis, mínimo e máximo obtidos no campo e utilizados para a simulação, estão apresentados nas Tabelas 8 a 10. Cabe salientar que, em relação a alimentação dos peixes, foi observado utilização de ração industrial para peixes, disponivel no mercado a custos menores (extrusada ou peletizada). 
Tabela 8 - Valores mais prováveis das variáveis consideradas aleatórias, limites superiores e inferiores estabelecidos para a simulação Região de Ribeirão Preto, SP

\begin{tabular}{lccc}
\hline \multicolumn{1}{c}{ Variável } & $\begin{array}{c}\text { Limite } \\
\text { Inferior }\end{array}$ & $\begin{array}{c}\text { Valor mais } \\
\text { Provável }\end{array}$ & $\begin{array}{c}\text { Limite } \\
\text { Superior }\end{array}$ \\
\hline Coeficiente Técnico & & & \\
-Sobrevivência $(\%)$ & 90 & 95 & 98 \\
-Densidade de estocagem $\left(\mathrm{n}^{\circ}\right.$ peixe $\left./ \mathrm{m}^{2}\right)$ & 0,8 & 1,0 & 1,5 \\
-Conv. Alim. Aparente $(\mathrm{kg}$ ração $/ \mathrm{kg}$ peixe) & 1,5 & 2,0 & 2,4 \\
-Peso final do pescado $(\mathrm{kg})$ & 0,8 & 1,0 & 1,3 \\
& & & \\
Preço (Julho/96) & 80,00 & 100,00 & 120,00 \\
-Preço do alevino (R\$/milheiro) & 2,50 & 2,80 & 3,00 \\
-Preço do pescado $(\mathrm{R} \$ / \mathrm{kg})$ & 0,38 & 0,40 & 0.49 \\
-Preço de ração $(\mathrm{R} \$ / \mathrm{kg})$ & 1,30 & 1,85 & 2,40 \\
-Preço de construção de viveiro $\left(\mathrm{R} \$ / \mathrm{m}^{2}\right)$ & & & \\
\hline
\end{tabular}

Tabela 9 - Valores mais prováveis das variáveis consideradas aleatórias, limites superiores e inferiores estabelecidos para a simulação Região do Vale do Ribeira, SP

\begin{tabular}{lccc}
\hline \multicolumn{1}{c}{ Variável } & $\begin{array}{c}\text { Limite } \\
\text { Inferior }\end{array}$ & $\begin{array}{c}\text { Valor mais } \\
\text { Provável }\end{array}$ & $\begin{array}{c}\text { Limite } \\
\text { Superior }\end{array}$ \\
\hline Coeficiente Técnico & 80 & 90 & 98 \\
-Sobrevivência (\%) & 0,8 & 1,0 & 1,5 \\
-Densidade de estocagem $\left(\mathrm{n}^{\circ}\right.$ peixe $\left./ \mathrm{m}^{2}\right)$ & 1,5 & 2,0 & 3,0 \\
-Conv. Alim. Aparente $(\mathrm{kg}$ ração $/ \mathrm{kg}$ peixe) & 1,5 & 1,0 & 1,4 \\
-Peso final do pescado $(\mathrm{kg})$ & 0,9 & & \\
& & & \\
Preço (Julho/96) & 80,00 & 90,00 & 100,00 \\
-Preço do alevino (R\$/milheiro) & 2,50 & 2,80 & 3,00 \\
-Preço do pescado $(\mathrm{R} \$ / \mathrm{kg})$ & 0,38 & 0,40 & 0.49 \\
-Preço de ração $(\mathrm{R} \$ \mathrm{~kg})$ & 1,30 & 1,85 & 2,40 \\
-Preço de construção de viveiro $\left(\mathrm{R} \$ / \mathrm{m}^{2}\right)$ & & & \\
\hline
\end{tabular}


Tabela 10 - Valores mais prováveis das variáveis consideradas aleatórias, limites superiores e inferiores estabelecidos para a simulação Região de Presidente Prudente, SP

\begin{tabular}{lccc}
\hline \multicolumn{1}{c}{ Variável } & $\begin{array}{c}\text { Limite } \\
\text { Inferior }\end{array}$ & $\begin{array}{c}\text { Valor mais } \\
\text { Provável }\end{array}$ & $\begin{array}{c}\text { Limite } \\
\text { Superior }\end{array}$ \\
\hline Coeficiente Técnico & & & \\
-Sobrevivência $(\%)$ & 90 & 95 & 98 \\
-Densidade de estocagem $\left(\mathrm{n}^{\circ}\right.$ peixe $\left./ \mathrm{m}^{2}\right)$ & 0,8 & 1,0 & 1,5 \\
-Conv. Alim. Aparente $(\mathrm{kg}$ ração $/ \mathrm{kg}$ peixe $)$ & 1,5 & 2,0 & 2,4 \\
-Peso final do pescado $(\mathrm{kg})$ & 0,8 & 1,0 & 1,2 \\
& & & \\
Preço (Julho/96) & 80,00 & 90,00 & 100,00 \\
-Preço do alevino $(\mathrm{R} \$ /$ milheiro $)$ & 2,50 & 2,80 & 3,00 \\
-Preço do pescado $(\mathrm{R} \$ / \mathrm{kg})$ & 0,38 & 0,40 & 0.49 \\
-Preço de ração $(\mathrm{R} \$ / \mathrm{kg})$ & 1,30 & 1,85 & 2,40 \\
-Preço de construção de viveiro $\left(\mathrm{R} \$ / \mathrm{m}^{2}\right)$ & & & \\
& & &
\end{tabular}

Foram efetuadas 100 simulações. As Tabelas 11 e 12 apresentam o resumo dos resultados para a região de Ribeirão Preto. As demais informaçōes geradas pelo ALEAXPRJ para as outras regiões se encontram no Apêndice 2. Devido a proximidade dos resultados evitou-se repetir os comentários e inferências sobre os valores obtidos. 
Tabela 11 - Simulação: valores médios e desvio-padrão dos indicadores econômicos - taxa de desconto de $6 \%$ a. a. - Região de Ribeirão Preto, SP

\begin{tabular}{lcc}
\hline \multicolumn{1}{c}{ Indicador } & Média & Desvio Padrão \\
\hline TIR $(\%)$ & 60,50 & 27,50 \\
VA (R\$) & $476.901,65$ & $248.730,35$ \\
RBC & 1,78 & 0,42 \\
PBS (periodos) & 2,62 & 1,30 \\
PBE (periodos) & 2,86 & 1,66 \\
CTA (R\$) & $616.986,25$ & $30.153,61$ \\
Custo Unit. Total (R\$/kg) & 1,64 & 0,37 \\
& & \\
\hline
\end{tabular}

Tabela 12 - Simulação: valores obtidos (máximo e minimo) para os indicadores econômicos - Região de Ribeirão Preto, SP

\begin{tabular}{lcc}
\hline \multicolumn{1}{c}{ Indicador } & Máximo & Mínimo \\
\hline TIR (\%) & 138,00 & \\
VA (R\$) & $1.146 .213,34$ & 10,60 \\
RBC & 3,10 & $33.670,04$ \\
PBS (periodos) & 9 & 1,05 \\
PBE (periodos) & 12 & 1 \\
CTA (R\$) & $678.744,02$ & 1 \\
Custo Unit. Total (R\$/kg) & 2,68 & $545.411,58$ \\
& & 0,89 \\
\hline
\end{tabular}

O valor obtido para a TIR foi de $60,5 \%$, com a probabilidade de $97,0 \%$ de ser superior a $20,0 \%$, valor limite estabelecido para a análise, indicando a grande atratividade do empreendimento, embora o desviopadrão de $27,5 \%$ possa ser considerado elevado. No conjunto das simulações, foram encontrados os valores máximo e minimo da TIR de $138,0 \%$ e $10,6 \%$, respectivamente. O Valor Atual e a Relação Benefício/Custo apresentam-se positivos, sendo que para a RBC foi 
encontrada a probabilidade de $69,0 \%$ de ser superior a 1,5 (limite estabelecido) e na média foi 1,78 , indicando um benefício líquido de $R \$ 0,78$ para cada $\mathrm{R} \$ 1,00$ dispendido na criação.

O tempo de recuperação de capital ficou em média 2,62 anos sem a inclusão da taxa de desconto e de 2,86 anos incluindo a taxa de desconto, com a probabilidade de apenas $23,0 \%$ ser superior a 3 anos, valor limite adotado para análise. A média do Custo Unitário Total foi de R\$1,64 com desvio-padrão de $R \$ 0,37$, indicando uma grande dispersão do resultado, mas também a boa remuneração do pescado tendo em vista os valores de venda final terem sido praticados entre $R \$ 2,50$ e $R \$ 3,00 / \mathrm{kg}$, proporcionando uma receita em torno de $\mathrm{R} \$ 1,00 / \mathrm{kg}$.

Analisando o empreendimento na região do Vale do Ribeira, através das Tabelas 13 e 14, encontra-se a TIR média de $66,80 \%$ com a probabilidade de $100 \%$ de ser superior a $20,00 \%$, valor limite adotado para a análise, apresentando-se viável, economicamente.

Tabela 13 - Simulação: valores médios e desvio-padrão dos indicadores econômicos - taxa de desconto de $6 \%$ a. a. - Região do Vale do Ribeira, SP

\begin{tabular}{lcc}
\hline \multicolumn{1}{c}{ Indicador } & Média & Desvio-Padrão \\
\hline & & \\
TIR (\%) & 66,80 & 30,70 \\
VA (R\$) & $519.364,83$ & $261.048,77$ \\
RBC & 1,86 & 0,44 \\
PBS (periodos) & 2,34 & 0,92 \\
PBE (períodos) & 2,50 & 1,05 \\
CTA (R\$) & $606.148,97$ & $32.352,05$ \\
Custo Unit. Total (R\$/kg) & 1,57 & 0,35 \\
& & \\
\hline
\end{tabular}


Tabela 14 - Simulação: valores obtidos (máximo e mínimo) para os indicadores econômicos - Região do Vale do Ribeira, SP

\begin{tabular}{lcc}
\hline \multicolumn{1}{c}{ Indicador } & Máximo & Minimo \\
\hline TIR (\%) & 151,3 & 22,2 \\
VA (R\$) & $1.107 .529,30$ & $131.186,33$ \\
RBC & 3,02 & 1,20 \\
PBS (periodos) & 5 & 1 \\
PBE (periodos) & 6 & 1 \\
CTA (R\$) & $674.452,44$ & $535.444,83$ \\
Custo Unit. Total (R\$/kg) & 2,33 & 0,93 \\
& & \\
\hline
\end{tabular}

A RBC média calculada com a simulação foi de 1,86 com $78,0 \%$ de probabilidade de ser superior a 1,5 (valor limite estabelecido para a análise de risco). Com relação ao periodo de recuperação de capital, foram encontrados valores próximos a 2,5 anos, com a inclusão ou não da taxa de desconto. Para o PBE obteve-se apenas $18,0 \%$ de probabilidade de encontrar um valor superior a 3 anos, conforme estabelecido para a análise. $O$ valor médio encontrado para o custo unitário total foi de $R \$ 1,57$, sendo que o produtor tem margem de segurança, mesmo sob condições de risco, de obter um custo inferior ao esperado, podendo chegar a $\mathrm{R} \$ 0,93$ conforme indicado na Tabela 14.

Os indicadores econômicos encontrados para a região de Presidente Prudente, após a simulação, encontram-se nas Tabelas 15 e 16. 
Tabela 15 - Simulação: valores médios e desvio-padrão dos indicadores econômicos - taxa de desconto de $6 \%$ a. a. - Região de Presidente Prudente, SP

\begin{tabular}{lcc}
\hline \multicolumn{1}{c}{ Indicador } & Média & Desvio-Padrão \\
\hline TIR (\%) & 0,68 & \\
VA (R\$) & $523.908,89$ & 0,32 \\
RBC & 1,87 & $278.311,36$ \\
PBS (períodos) & 2,31 & 0,47 \\
PBE (períodos) & 2,59 & 1,21 \\
CTA (R\$) & $609.425,66$ & 1,51 \\
Custo Unit. Total (R\$/kg) & 1,58 & $30.327,24$ \\
& & 0,38 \\
\hline
\end{tabular}

Tabela 16 - Simulação: valores obtidos (máximo e mínimo) para os indicadores econômicos - Região de Presidente Prudente, SP

\begin{tabular}{lcc}
\hline \multicolumn{1}{c}{ Indicador } & Máximo & Mínimo \\
\hline TIR (\%) & 134,20 & 11,60 \\
VA (R\$) & $1.106 .339,74$ & $34.639,09$ \\
RBC & 2,893 & 1,054 \\
PBS (periodos) & 8 & 1 \\
PBE (periodos) & 10 & 1 \\
CTA (R\$) & $666.976,11$ & $533.627,43$ \\
Custo Unit. Total (R\$/kg) & 2,63 & 0,96 \\
& & \\
\hline
\end{tabular}

A TIR média obtida foi de $67,50 \%$. Considerando o valor limite para a TIR de $20 \%$ para efeito de avaliação de risco, conclui-se que há $97 \%$ de probabilidade dos produtores pertencentes à região de Presidente Prudente obterem uma TIR superior a este valor. $O$ indicador econômico RBC encontrado foi de 1,87. O limite estabelecido foi de 1,5, encontrando assim a probabilidade de $77 \%$ de obter uma RBC superior ao limite. 
Para a região de Presidente Prudente foi encontrado o valor médio do Custo Unitário Total de $\mathrm{R} \$ 1,58$ com desvio padrão de $\mathrm{R} \$ 0,38$. Para o PBS e PBE, os valores médios foram 2,31 anos e 2,59 anos, respectivamente, sendo que para o limite estabelecido de 3 anos, tem-se apenas $14,0 \%$ de probabilidade de ser superior a esse limite.

A título de informação, a tabela 17 apresenta resultados econômicos obtidos através do método de Monte Carlo para outras atividades pecuárias. Entre essas, verifica-se que a aqüicultura (Amaral, 1989) apresenta resultados próximos aos obtidos no presente estudo.

Tabela 17 - Resultados econômicos obtidos, para outras atividades pecuárias, através do Método de Monte Carlo

\begin{tabular}{|c|c|c|c|}
\hline Autor/Ano & Item & Indicador & Desvio-padrão \\
\hline \multirow[t]{3}{*}{ Sá (1985) } & Confinamento de & TIR(\%) 11,05; 6,55; & \\
\hline & bovino & 17,$44 ; \quad 2,12$ e - & - \\
\hline & & 16,41 & \\
\hline \multirow[t]{2}{*}{ Amaral (1989) } & Criação de pós- & $\operatorname{TIR}(\%) \quad 76,1 ; \mathrm{RBC}$ & \\
\hline & larvas de camarão & 2,5 e PBE 2,3 anos & - \\
\hline \multirow[t]{3}{*}{ Neves et al. (1993) } & Confinamento de & $\operatorname{TIR}(\%) 9,7$ & 5,60 \\
\hline & bovino & RBC 1,01 & 0,02 \\
\hline & & PBE 10,77 anos & 3,17 \\
\hline \multirow[t]{3}{*}{ Araújo (1996) } & Criação de frango & TIR (\%) 12,81; & \\
\hline & de corte & 18,$66 ; \quad 17,73 \quad$ e & - \\
\hline & & 16,91 & \\
\hline
\end{tabular}




\section{4 - CONCLUSÃO}

Os resultados encontrados apresentam-se próximos para as três regiōes, com pequena diferenciação para a região de Ribeirão Preto, que apresentou um valor maior para a terra. As regiōes de Presidente Prudente e Vale do Ribeira tinham preços cerca de $35 \%$ do valor da terra na região de Ribeirão Preto.

O custo unitário total simulado da criação de pacu foi de $R \$$ $1,64 / \mathrm{kg}$ na região de Ribeirão Preto, $R \$ 1,57 / \mathrm{kg}$ na região do Vale do Ribeira, e $R \$ 1,58 / \mathrm{kg}$ na região de Presidente Prudente, com respectivos desvios padrão de $\mathrm{R} \$ 0,37 ; \mathrm{R} \$ 0,35$ e $\mathrm{R} \$ 0,38$.

Confrontando os valores obtidos de custo unitário com os preços recebidos pelos produtores, os quais variaram de $R \$ 2,50$ a $R \$$ $3,00 / \mathrm{kg}$, conclui-se que são pequenos os riscos de se obter um custo unitário superior a esses valores.

Ao ser atribuida a taxa minima de atratividade de $6 \%$ a. a. para $a$ análise de risco do empreendimento, conclui-se que todas as regiões têm condições de obter taxas superiores, conforme os resultados obtidos para a TIR de $60,5 \%$ na região de Ribeirão Preto, $66,8 \%$ na região do Vale do Ribeira e $67,5 \%$ na região de Presidente Prudente. Através do indicador $\mathrm{RBC}$ pode-se inferir que a atividade apresenta boa atratividade, pois o valor mínimo observado na simulação revelou uma RBC acima da unidade. 
Observando os valores obtidos pelas simulações, pode-se verificar que são altas as possibilidades dos produtores obterem resultados econômicos superiores aos alcançados na avaliação determinística, nas regiões estudadas.

O Payback inferior a 3 anos sugere a rápida recuperação do capital investido, tornando a atividade menos sujeita às incertezas futuras. Por outro lado, a grande dispersão dos valores observados pelos desvios padrão faz com que a criação de pacu seja vista como uma atividade de risco.

Os retornos médios elevados, indicam boa atratividade para o investimento, já que o período de recuperação do capital obtido foi reduzido. $\mathrm{E}$, quanto menor este periodo (payback) maior a liquidez e menor o risco envolvido.

Pela análise de trabalhos disponiveis na literatura, observouse resultados semelhantes obtidos por Amaral (1989), com a criação de pós-larvas de camarão, encontrando TIR de 76,1\%, RBC de 2,5 e PBE de 2,3 anos.

No presente momento, o grande número de produtores que estão ingressando na atividade estariam confirmando os bons resultados obtidos.

Como sugestão recomenda-se aos investidores no setor, a revisão periódica dos preços dos fatores de produção e do produto final, pois a atratividade do investimento está diretamente relacionada a eles. $A$ entrada na atividade de um maior número de produtores podẹria induzir 
variações nos preços dos fatores de produção, face a maior demanda. Por sua vez, a competitividade e a maior oferta do produto no tempo poderão estabelecer preços menores para a piscicultura. 


\section{REFERÊNCIAS BIBLIOGRÁFICAS}

AMARAL, A. M. P., Análise econômica da produção de pós-larvas do camarão de água-doce Macrobrachium rosembergii. Piracicaba: Escola Superior de Agricultura Luiz de Queiróz - ESALQ/USP, 1989. 91 p. Dissertação (Mestrado).

ARRUDA, S. T. Análise econômica da produção da borracha natural no Estado de São Paulo. Piracicaba: Escola Superior de Agricultura Luiz de Queiróz - ESALQ/USP, 1986. 114 p. Dissertação (Mestrado).

AZEVEDO FILHO, A. J. de B. V. Análise econômica de Projeto: "Software" para situações deterministas e de risco envolvendo simulação. Piracicaba: Escola Superior de Agricultura Luiz de Queiróz - ESALQ/USP, 1988. 127 p. Dissertação (Mestrado).

AZEVEDO, P. A piscicultura, histórico, considerações gerais e perspectivas futuras. In: Poluição e Piscicultura. São Paulo: Comissão Interestadual da Bacia Paraná-Uruguai, Faculdade de Saúde Pública da USP, 1972. p. 177-180.

BRUNELLI, G. M. Simulação do custo de produção de laranja no Estado de São Paulo. Piracicaba: Escola Superior de Agricultura Luiz de Queiróz - ESALQ/USP, 1990. 99 p. Dissertação (Mestrado).

CASTAGNOLLI, N., CAMARGO, A. F., OLIVEIRA, G. T. et al. Influência da estação do ano e do fertilizante aplicado na produção orgânica de tanques. II. Produção secundária e de peixes. Bol. Inst. de Pesca, v. 9, n. único, p. 100-123, 1982.

CASTAGNOLLI, N., OLIVEIRA, G. T., OSTINI, S. et al. Influência da estação do ano e do fertilizante aplicado na produção orgânica de tanques. I. Produção primária e peixes. Bol. Inst. de Pesca, v. 9, n. único, p. 91108, 1982.

CASTAGNOLLI, N. \& ZUIM, S. M. F. Consolidação do conhecimento adquirido sobre o pacu, Colossoma mitrei, Berg 1895. Jaboticabal: UNESP, 1985, $30 \mathrm{p}$. 
CHABALIN, E., FERRAZ DE LIMA, J. A. Análise econômica de um cultivo intensivo de pacu (Colossoma mitrel) no Centro-Oeste do Brasil. B. Téc. CEPTA, v. 1, n. 1, p. 61-68, 1988.

CHABALIN, E., FERRAZ DE LIMA, J. A., ALVES, L. B. O. Análise comparativa entre o valor comercial do pacu (Colossoma mitrei) capturado e cultivado - Mercado de Peixes de Cuiabá. B. Téc. CEPTA, v. 1, n. 1, p. $49-60,1988$.

CHABALIN, E., SENHORINI, J. A., FERRAZ DE LIMA, J. A. Estimativa do custo de produção de larvas e alevinos. B. Téc. CEPTA, v. 2, n. único. p. 61-74, 1989.

CHABALIN, E., PALHARES, F., FERRAZ DE LIMA, J. A. et al. Viabilidade econômica da utilização de resíduos hortifrutigranjeiros na criação de pacu Piaractus mesopotamicus em gaiolas. B. Téc. CEPTA, v. $5, \mathrm{n}$. único. p. 23-30, 1992.

CONTADOR, C. R. Custo de oportunidade do capital em condições de risco. Pesq. Plan. Econ., Rio de Janeiro, v.5, n. 1, p. 163-218, jun. 1975.

CONTADOR, C. R. Avaliação social de projetos. São Paulo: Atlas, 1981. $301 \mathrm{p}$.

CONTINI, E., ARAÚJO, J. D. de, GARRIDO, W. E. Instrumental econômico para a decisão na propriedade agrícola. In: Planejamento da propriedade agrícola; modelos de decisão. Brasilia: EMBRAPADDT, 1984. p. 7-22.

CRUZ, E. R. da. Aspectos teóricos sobre incorporação de riscos em modelos de decisão. In: Planejamento da Propriedade Agrícola: Modelos de Decisão. Brasília: EMBRAPA-DDT, 1984. p.237-260.

FAO. La acuicultura en Brasil. Informes de pesca, v. 3, n. 159. 1974.

FAO. Aquaculture Production 1984-1990. FAO Fish. Circ., n. 815 (Rev. 4), 206 p. 1992.

FAO. Review of the state of world fishery resources: aquaculture. FAO Fish. Circ., n. 886, 127 p. 1995. 
FARO, C. de Critérios quantitativos para avaliação e seleção de projetos de investimentos. Rio de Janeiro: IPEA, INPES, 1971. 142 p. (Monografia n. 2).

FERRAZ DE LIMA, J. A. A pesca no Pantanal de Mato Grosso (rio Cuiabá: importância dos peixes migradores). Acta Amazônica, v. 16/17, n. único, p. 87-94. 1986/1987.

FERRAZ DE LIMA, J. A., SOUZA, J. H., BUSTAMANTE, A. et al. Recomendações técnicas para a criação de pacu Piaractus mesopotamicus em viveiros. Red Acuicultura Bol., Bogotá, v. 6, n. 2, p. 8, abril-junio, 1992.

FERREIRA JÚNIOR, M. G., SILVA, A. L. , ROSA, M. C. G. Contribuição ao estudo da análise bioeconômica do cultivo intensivo do catfish africano (Clarias gariepinus) associado a curimatā pacu (Prochilodus argenteus) no nordeste brasileiro. SIMPÓSIO BRASILEIRO DE AQÜICULTURA, 8, 1994, Piracicaba. Resumo, p. 128.

HERNANDEZ R., A. (ed.). Cultivo de Colossoma. Bogotá: Editora Guadalupe, 1989. 475 p.

IBGE. Anuário Estatístico do Brasil. Fundação Instituto Brasileiro de Geografia e Estatística, Ano 1, 1992. 1116 p.

LATAPIA, M. X. I. C. Custos da produção agrícola sob condiçōes de risco no Estado de São Paulo. Piracicaba: Escola Superior de Agricultura Luiz deQueiróz - ESALQ/USP, 1988. 93 p. Dissertação (Mestrado).

LEBOUTE, E. M., WINCKLER, L. T., ZIMMERMANN, S. et al. Avaliação dos principais custos operacionais de um cultivo de tilápia-do-nilo, Oreochromis niloticus, em gaiolas flutuantes na região da campanha do Estado do Rio Grande do Sul. SIMPÓSIO BRASILEIRO DE AQÜICULTURA, 8, 1994, Piracicaba. Resumo, p. 130.

MARTIN, N. B., SCORVO FILHO, J. D., SANCHES, E. G. Custos e retornos na piscicultura em São Paulo. Inf. Econ., São Paulo, v. 25, n. 1, p. 1047, jan. 1995.

$\mathrm{NASH}, \mathrm{C}$. E. Future economic outlook for aquaculture and related assistence needs. FAO, ADCP/REP/87/25, 14 p., 1987. 
NEIVA, G. S. Subsídios para a política pesqueira nacional. Terminal Pesqueiro de Santos, (s. I.; s. n.), 1990. 64 p.

NEVES, E. M., Análise econômica do investimento em condiçōes de risco na cultura da borracha. Piracicaba: Escola Superior de Agricultura Luiz de Queiróz - ESALQ/USP. 1984, 171 p. (Livre Docência).

NEVES, E. M., AZEVEDO FILHO, A.J. B. V. Avaliação de investimentos em condições de risco: uma aplicação na cultura da borracha envolvendo simulação. SIMPÓSIO BRASILEIRO DE PESQUISA OPERACIONAL, 18, 1985, São José dos Campos, Anais... Instituto Tecnológico da Aeronáutica, p. 46-63.

NEVES, E. M.,COUTO, M. T. Confinamento de bovinos de corte: condicionantes econômicos e instrumentos de apoio à tomada de decisão. In: Peixoto, A.M., Moura, J. C., FAFIA, V. P. (eds.), Confinamento de bovinos de corte. Piracicaba: FEALQ, Série Atualização em Zootecnica, v. 2, 1987.

NEW, M.,SHEHADEH, Z., PEDINI, M. Status and trends in food production through aquaculture. FAO Aquaculture Newsletter, n. 9, p. 12-18, 1995.

NORONHA, J. F. Projetos agropecuários: administrção financeira, orçamento e viabilidade econômica. São Paulo: Atlas, 1987. 269 p.

PAULA, J. E. de., MORAES FILHO, M. B., BERNARDINO, G. et al. Estudo da vegetação relacionada com a alimentação do pacu (Colossoma mitrei Berg, 1895) no Pantanal Mato-Grossense. Acta Bot. Bras., v. 2, n. 1, p. 73-96, 1989.

PORTZ, L., SIMONI, M. R. F., CRISÓSTOMO, L. C. et al. Análise econômica do consorciamento do camarão gigante da malásia com tilápia nilótica e com carpa comum. SIMPÓSIO BRASILEIRO AQÜICULTURA, 8, 1994, Piracicaba, Resumo, p. 133.

SÁ, J. M. de Análise econômica da engorda de bovinos em confinamento, em Goiás. Piracicaba. Escola Superior de Agricultura Luiz de Queiróz - ESALQ/USP, 1985. 111 P. Dissertação (Mestrado). 
SAINT-PAUL, U. Recent developments and prospects of cultured indigenous freshwater fish in Latin America. In: Verreth, J. A.J., Carrillo, M., Zauny, S., Huisman, E. A. (eds), Investigación acuicola en America Latina. Proceedings del Taller de Trabajo sobre Acuicultura en America Latina, Lima, Peru. Wageningen: Pudoc, 1987. p. 9-22.

SECRETAN, P. A. D., NASH, C. E. Aquaculture and risk management. FAO, ADCP/REP/89/41, 32 p., 1989.

SHANG, Y. C. Aquaculturre economic analysis: an introduction. Baton Rouge: The World Aquaculture Society, 1990. 211 p. (Advances in World Aquaculture, v. 2).

SOBUE, S. N., CASTAGNOLLI, N., PITELLI, R. A. Biotic productivity in fish ponds. Rev. Bras. Biol., v. 37, n. 4, p. 761-769, 1977.

SOBUE, S. Efeitos de diferentes fertilizantes orgânicos na produção de tanques de criação de peixes. Jaboticabal, SP, UNESP - FCAV, 1980. Dissertação (Mestrado).

TACON, A. G. J. Aquaculture nutrition: food for thought. FAO Aquaculture Newsl., n. 3, p. 2-6, 1993.

TORLONI, C. E. C., REIS, M. A. G., SICILIANO, S. F. et al. Análise quantitativa e econômica numa criação de pacu Piaractus mesopotamicus (Holmberg, 1887) em propriedade rural do Vale do Ribeira, Estado de São Paulo, São Paulo: CESP, 1991. 17 p. (Série Pesq. e Desenv. n. 061). 


\section{APÊNDICE 1:}

COMPOSIÇÃO DOS CUSTOS DE INVESTIMENTOS E OPERACIONAIS 
Tabela 1.1. - Investimento inicial para a criação de pacu, em uma área de 3ha de espelho d'água de viveiros, para as regiōes de Ribeirão Preto, Vale do Ribeira e Presidente Prudente (Estado de São Paulo)

\begin{tabular}{lccrrr}
\hline \multicolumn{1}{c}{ Item } & $\begin{array}{c}\text { Quanti- } \\
\text { dade }\end{array}$ & $\begin{array}{c}\text { Vida } \\
\text { Útil } \\
\text { (anos) }\end{array}$ & $\begin{array}{c}\text { Valor } \\
\text { Unit. R\$ }\end{array}$ & \multicolumn{1}{c}{$\begin{array}{c}\text { Valor } \\
\text { Total R\$ }\end{array}$} & \multicolumn{1}{c}{$\begin{array}{c}\text { Valor } \\
\text { Residual R\$ }\end{array}$} \\
\hline Projeto & 1 & - & $1.500,00$ & $1.500,00$ & 0,00 \\
Depósito & 1 & 30 & $2.500,00$ & $2.500,00$ & 250,00 \\
Viveiros & 3 ha & 20 & $18.500,00$ & $55.500,00$ & 0,00 \\
Veículo & 1 & 10 & $13.000,00$ & $13.000,00$ & 0,00 \\
Balança (300kg) & 1 & 20 & 520,00 & 520,00 & 0,00 \\
Balança (2kg) & 1 & 20 & 680,00 & 680,00 & 0,00 \\
Rede 25m & 1 & 10 & 400,00 & 400,00 & 0,00 \\
Potenciômetro & 1 & 20 & 870,00 & 870,00 & 0,00 \\
Oximetro & 1 & 30 & 1200,00 & $1.200,00$ & 120,00 \\
Aerador 1 hp & 10 & 20 & 500,00 & $5.000,00$ & 0,00 \\
& & & & & \\
Total & - & - & & $81.170,00$ & 370,00 \\
& & & & &
\end{tabular}

Nota: No décimo ano ocorre a reposição da rede de arrasto e do veículo. 
Tabela 1.2. - Custo operacional anual de produção de pacu em área de 3ha de espelho d'água - Região de Ribeirão Preto, SP

\begin{tabular}{lcrr}
\hline \multicolumn{1}{c}{ Item } & Quantidade & Valor Unit. R\$ & Valor Total R\$ \\
\hline Alevinos ( $n^{\circ}$ de indivíduos) & 31.600 & 0,10 & $3.160,00$ \\
Ração $(\mathrm{kg})$ & 60.000 & 0,40 & $24.000,00$ \\
Fertilizante $(\mathrm{t})$ & 75 & 17,00 & $1.275,00$ \\
Calcário $(\mathrm{t})$ & 39 & 47,00 & $1.833,00$ \\
Salários e Encargos & - & - & $10.800,00$ \\
Assistência técnica (visita) & 12 & 150,00 & $1.800,00$ \\
Energia elétrica & - & - & $1.500,00$ \\
Aluguel da terra & - & - & $1.200,00$ \\
Despesas gerais & - & - & $1.331,00$ \\
Total & - & - & $46.959,00$ \\
\hline
\end{tabular}


Tabela 1.3. - Custo operacional anual de produção de pacu em área de 3 ha de espelho d'água - Região do Vale do Ribeira, SP

\begin{tabular}{lcrr}
\hline \multicolumn{1}{c}{ Item } & Quantidade & Valor Unit. R\$ & Valor Total R\$ \\
\hline Alevinos ( $\mathrm{n}^{\circ}$ de indivíduos) & 33.340 & 0,09 & $3.000,60$ \\
Ração $(\mathrm{kg})$ & 60.000 & 0,40 & $24.000,00$ \\
Fertilizante $(\mathrm{t})$ & 75 & 17,00 & $1.275,00$ \\
Calcário (t) & 39 & 47,00 & $1.833,00$ \\
Salários e Encargos & - & - & $10.800,00$ \\
Assistência técnica (visita) & 12 & 150,00 & $1.800,00$ \\
Energia elétrica & - & - & $1.500,00$ \\
Aluguel da terra & - & - & 420,00 \\
Despesas gerais & - & - & $1.331,00$ \\
Total & - & & $45.959,60$ \\
\hline
\end{tabular}


Tabela 1.4 - Custo operacional anual de produção de pacu em área de 3 ha de espelho d'água - Região de Presidente Prudente, SP

\begin{tabular}{lcrr}
\hline \multicolumn{1}{c}{ Item } & Quantidade & Valor Unit. R\$ & Valor Total R\$ \\
\hline Alevinos ( ${ }^{\circ}$ de indivíduos) & 31.600 & 0,09 & $2.844,00$ \\
Ração $(\mathrm{kg})$ & 60.000 & 0,40 & $24.000,00$ \\
Fertilizante $(\mathrm{t})$ & 75 & 17,00 & $1.275,00$ \\
Calcário $(\mathrm{t})$ & 39 & 47,00 & $1.833,00$ \\
Salários e Encargos & - & - & $10.800,00$ \\
Assistência técnica (visita) & 12 & 150,00 & $1.800,00$ \\
Energia elétrica & - & - & $1.500,00$ \\
Aluguel da terra & - & - & 390,00 \\
Despesas gerais & - & - & $1.331,00$ \\
Total & - & - & $45.773,00$ \\
\hline
\end{tabular}


APÊNDICE 2:

RESULTADOS DA ANÁLISE DETERMINISTICA E DE RISCO PARA A PRODUÇÃO DE PACU 


\section{UNIVERSIDADE DE SAO PAULO}

C I A G R I - Centro de Informatica na Agricultura

Sistema de Analise de Projetos em Condicoes Deterministas -- Versao 1.0 --

Dados Gerais Sobre o Projeto

Nome do Projeto : ANALISE DE INVESTIMENTO EM PISCICULTURA

Analista : LUIS HENRIQUE ANDIA

Nome do Arquivo : PEIXERP6.PRJ Data : 25.09.96

Custo de Oportunidade : $6.00 \%$

Indicadores de Rentabilidade do Projeto

Valor Atual

Taxa Interna de Retorno ...

Relacao Beneficio/Custo ...

Payback Simples ..........

Payback Economico

Custos Totais Atualizados..
338735.78

$45.43 \%$

1.54

3.00 periodo(s)

3.00 periodo(s) 
UNIVERSIDADE DE SAO PAULO

C I A G R I - Centro de Informatica na Agricultura

Sistema de Analise de Projetos em Condicoes Deterministas -- Versao 1.0 --

\section{Dados Gerais Sobre o Projeto}

Nome do Projeto : ANALISE DE INVESTIMENTO EM PISCICULTURA

Analista : LUIS HENRIQUE ANDIA

Nome do Arquivo: PEIXERP9.PRJ Data : 25.09 .96

Custo de Oportunidade : $9.00 \%$

Indicadores de Rentabilidade do Projeto

Valor Atual

Relacao Beneficio/

Payback Simples .........

Payback Economico ........

Custos Totais Atualizados..
252748.48

$45.43 \%$

1.49

3.00 periodo(s)

3.00 periodo(s) 


\section{UNIVERSIDADE DE SAO PAULO}

C I A G R I - Centro de Informatica na Agricultura

Sistema de Analise de Projetos em Condicoes Deterministas -- Versao 1.0 --

Dados Gerais Sobre o Projeto

Nome do Projeto : ANALISE DE INVESTIMENTO EM PISCICULTURA

Analista : LUIS HENRIQUE ANDIA

Nome do Arquivo: PEIXRP12.PRJ Data : 25.09.96

Custo de Oportunidade : $12.00 \%$

Indicadores de Rentabilidade do Projeto

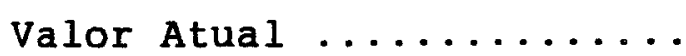

Taxa Interna de Retorno ...

Relacao Beneficio/Custo ...

Payback Simples .........

Payback Economico ........

Custos Totais Atualizados..
192032.68

$45.43 \%$

1.44

3.00 periodo(s)

3.00 periodo(s) 


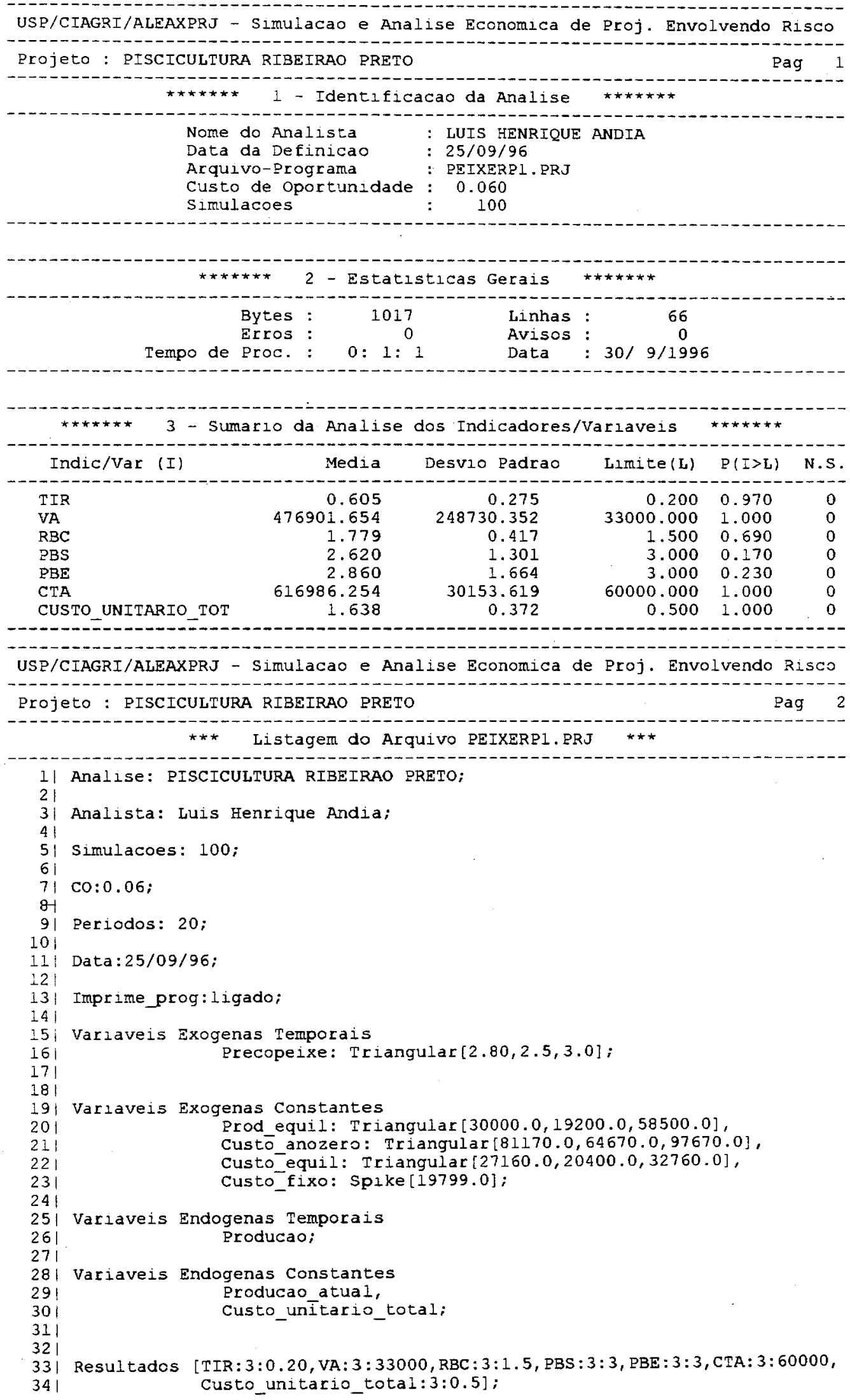




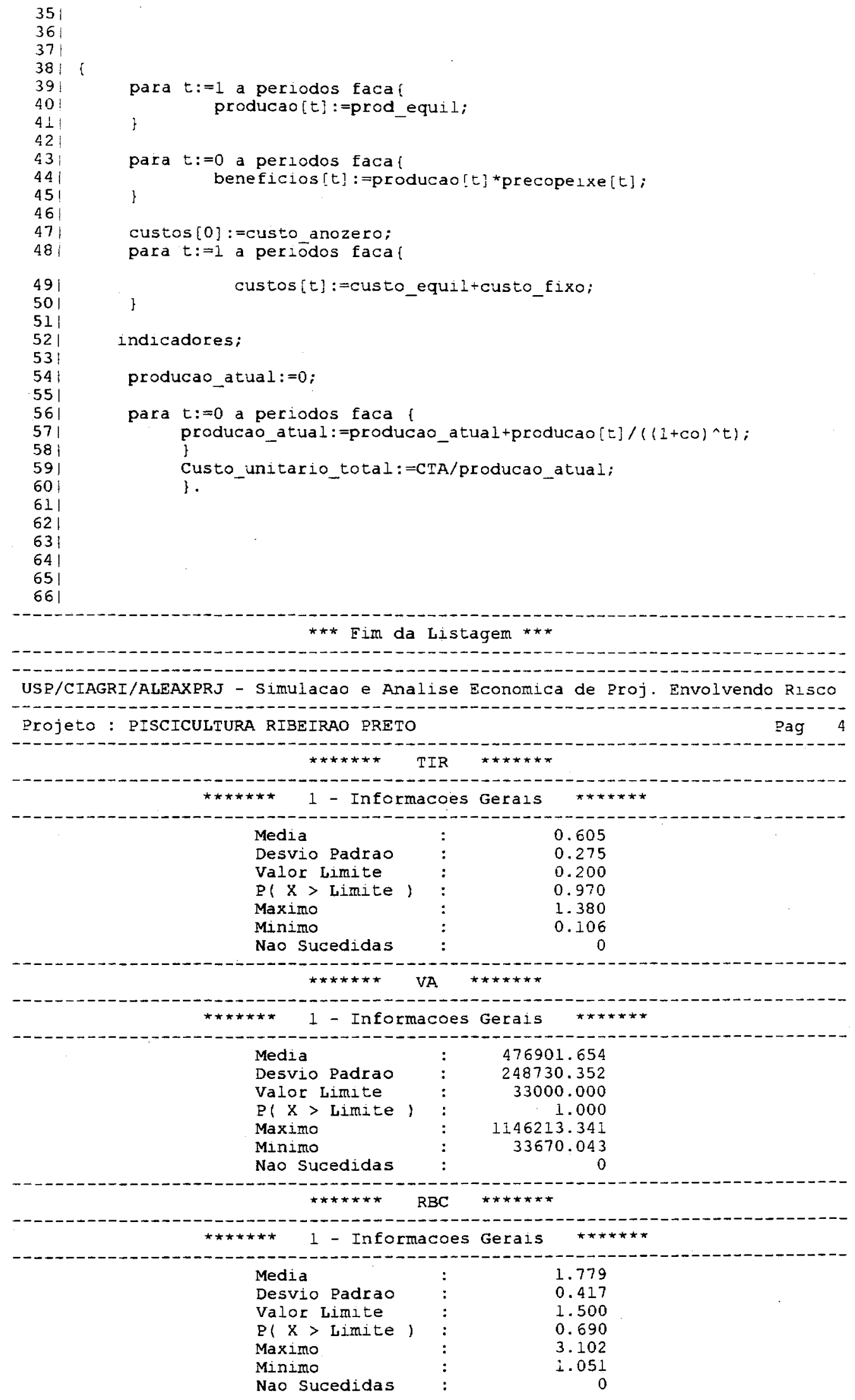




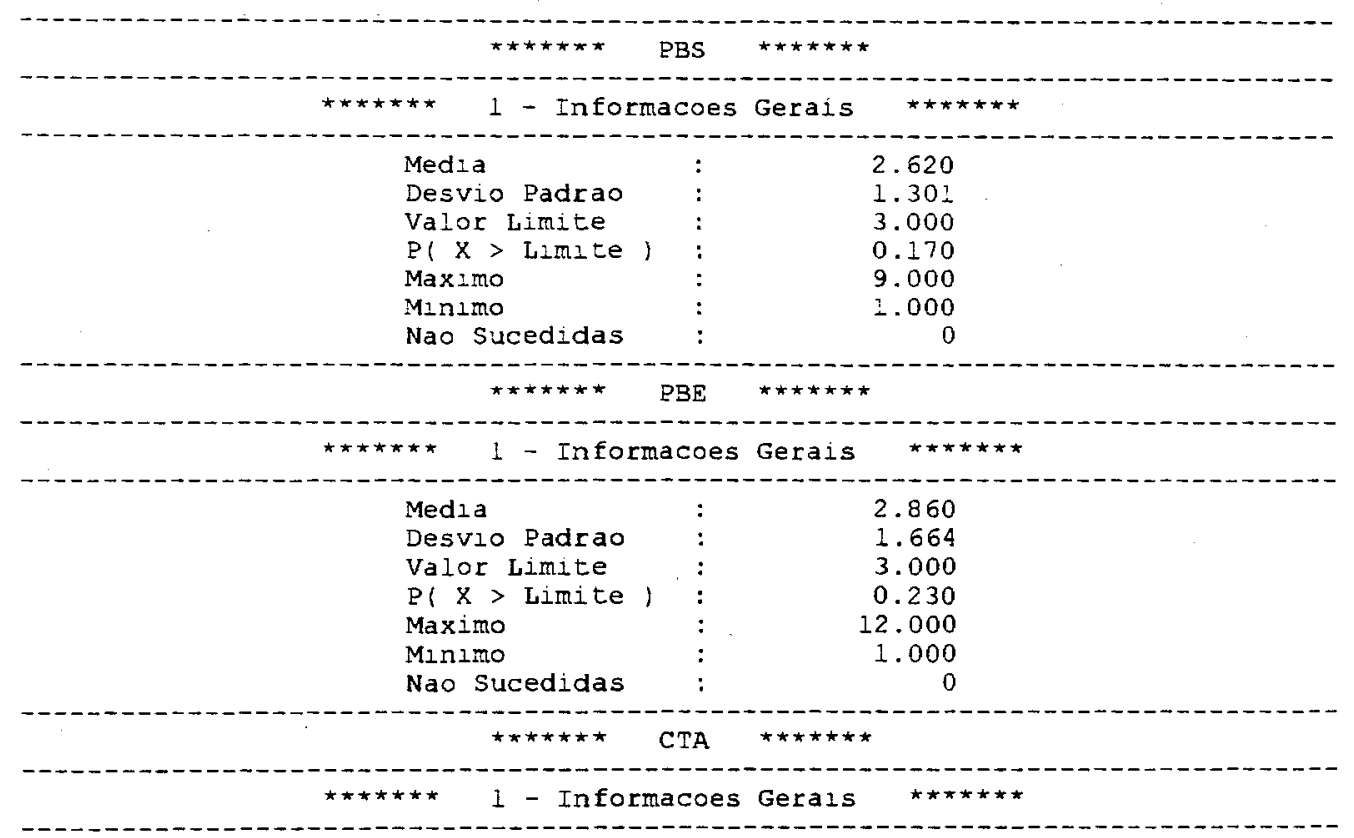

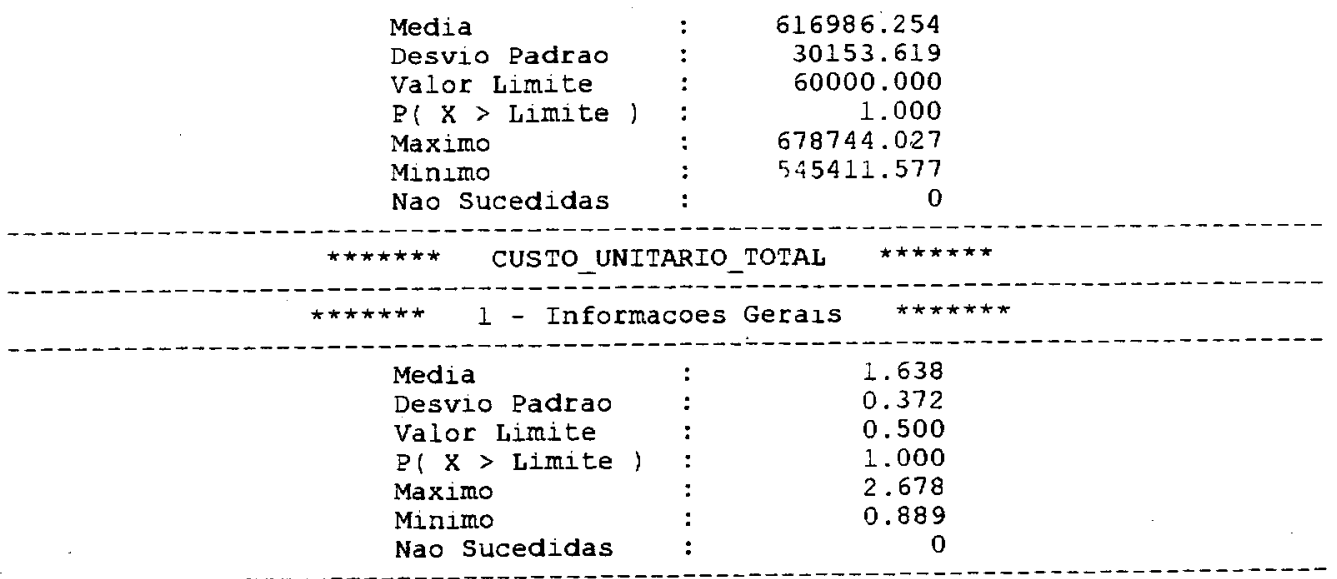




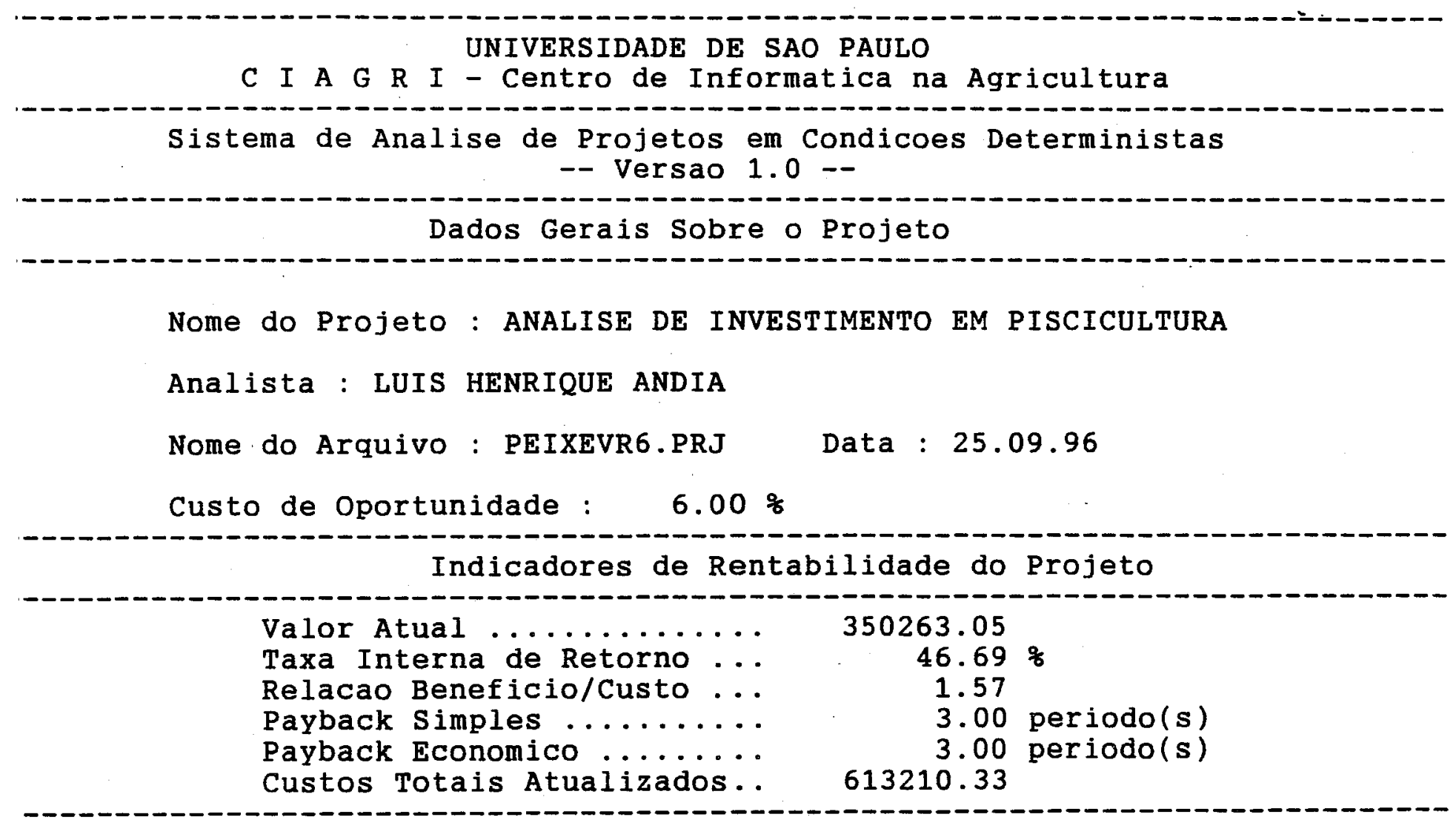




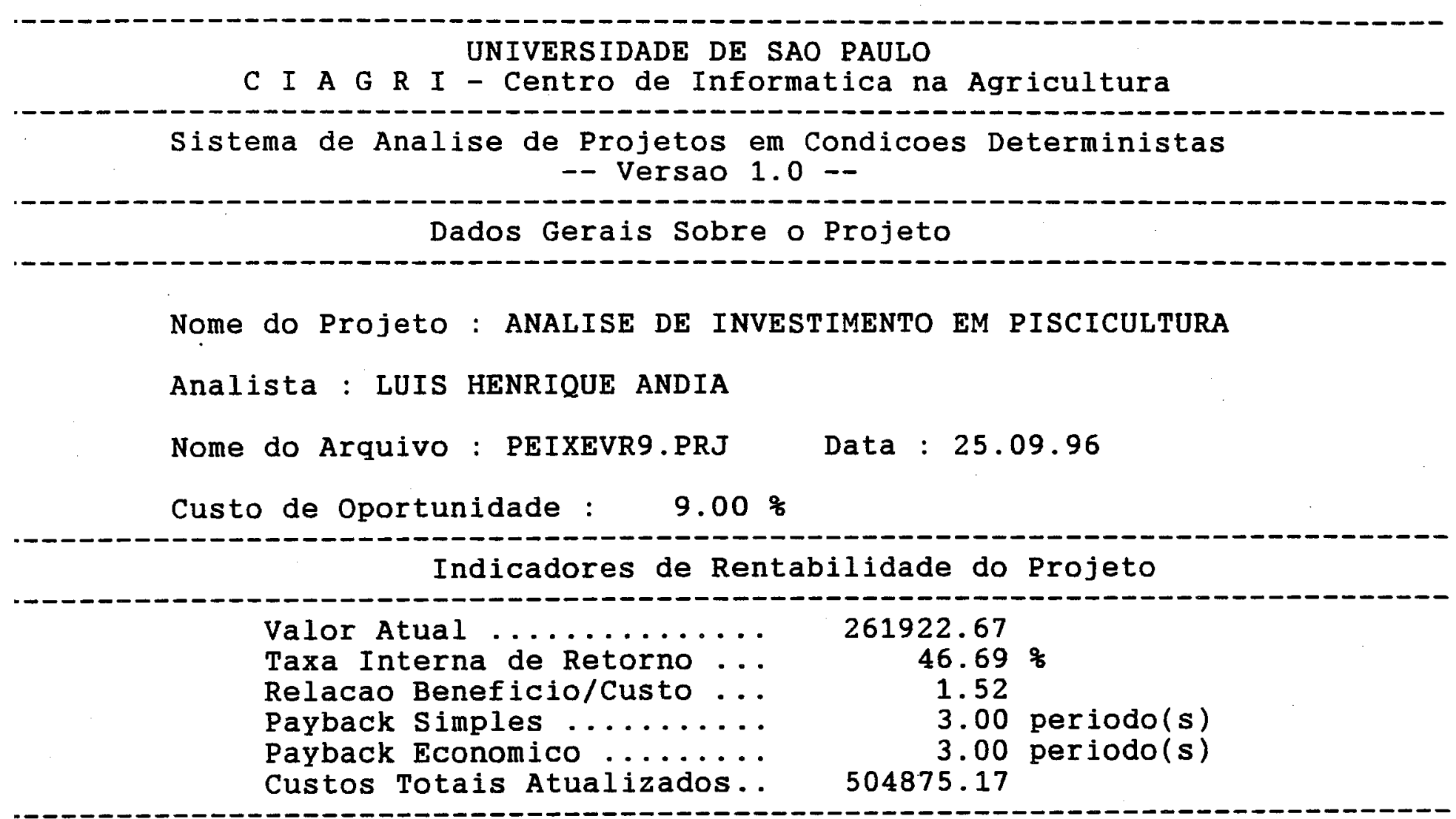




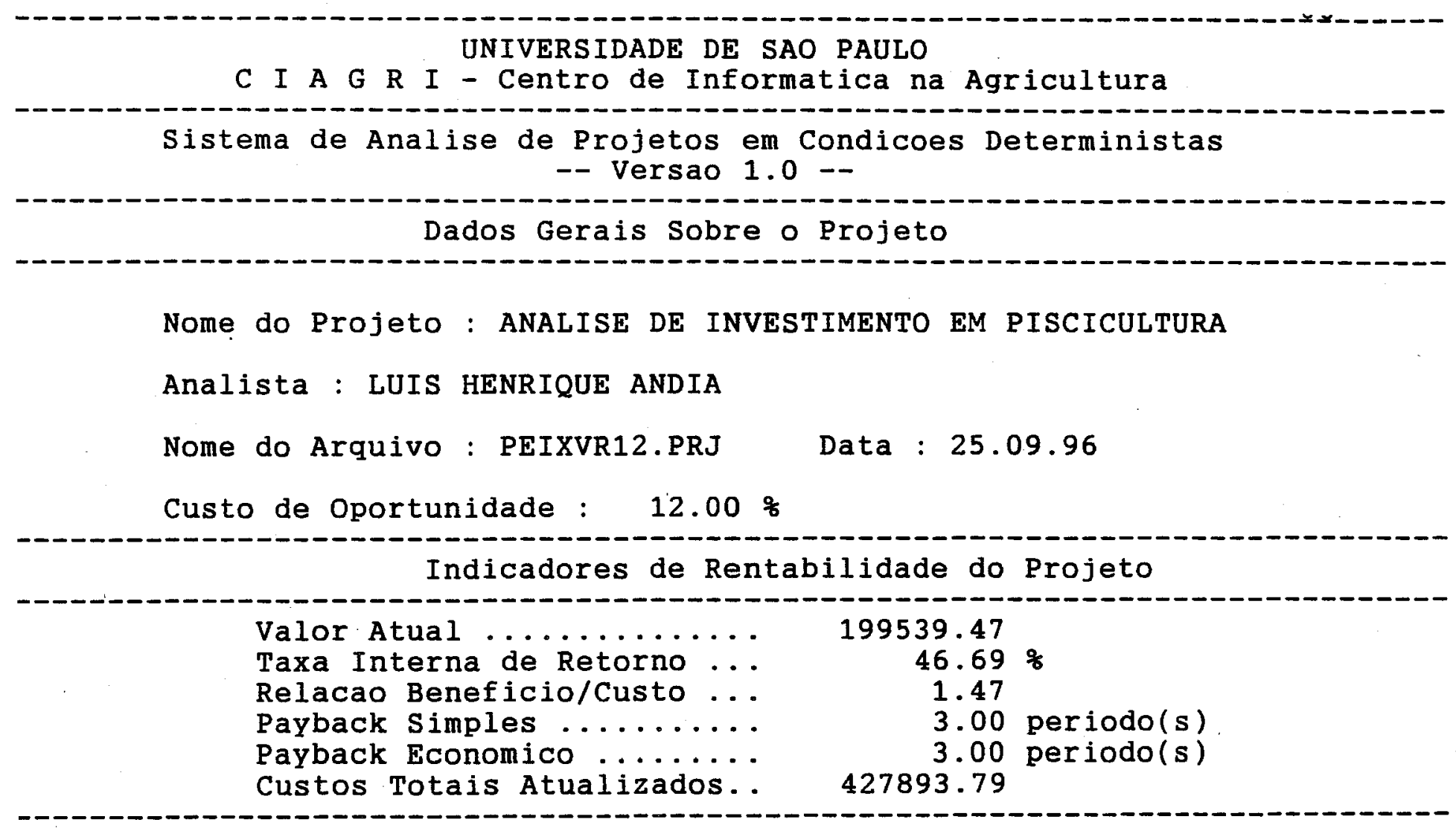




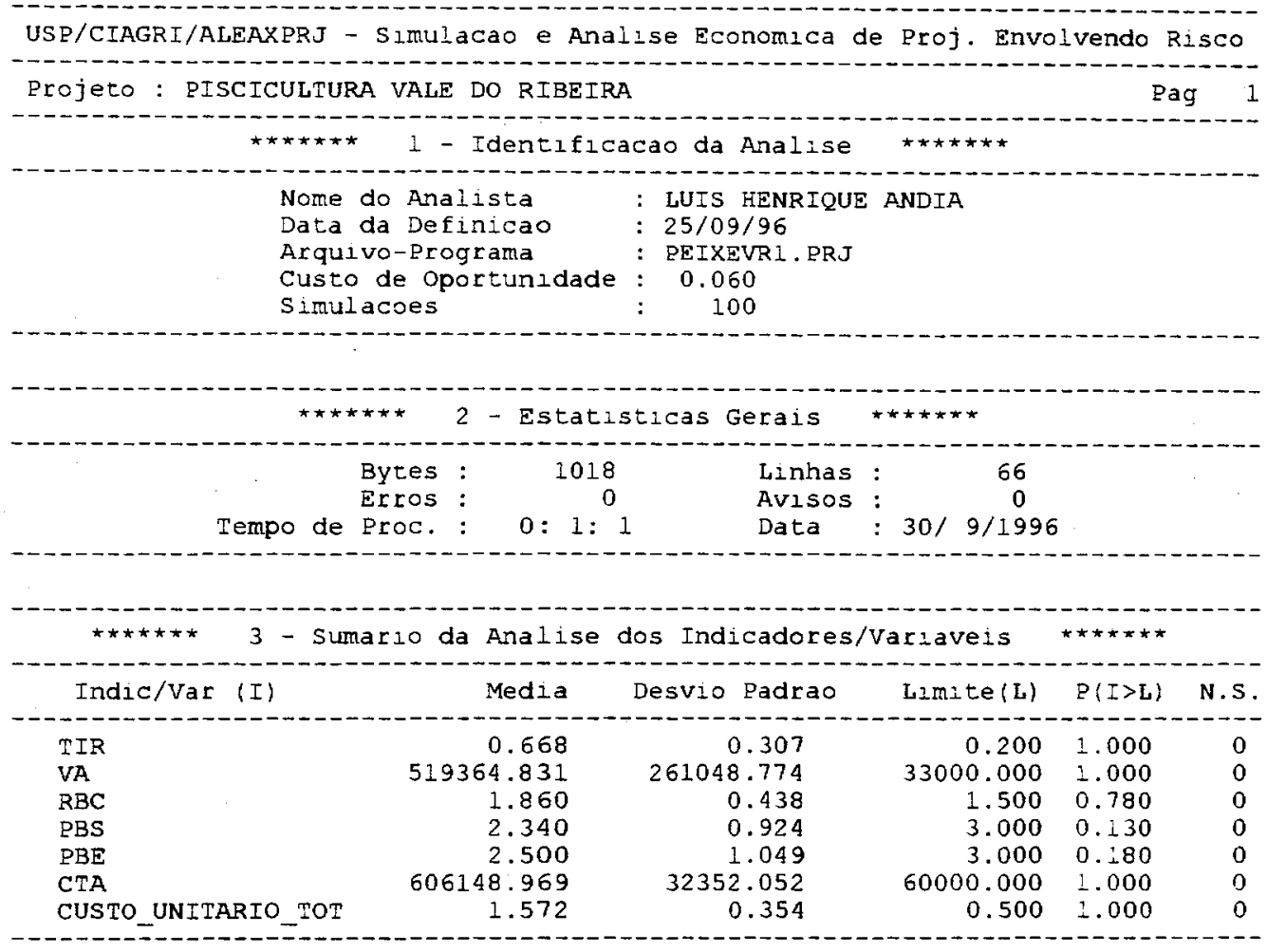

-

USP/CIAGRI/ALEAXPRJ - Simulacao e Analise Economica de 2roj. Envolvendo Risco

Projeto : RISCICULTURA VALE DO RIBEIRA $\quad$ Pag 2

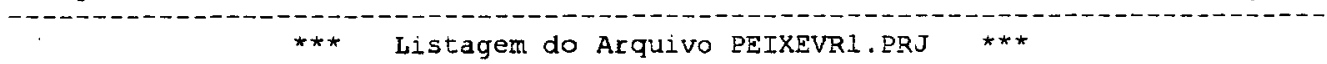

1 Analise: PISCICULTURA VALE DO RIBEIRA;

3) Analista: Luis Henrique Andia;

Simulacoes: 100;

$\mathrm{CO}: 0.06$

Periodos: 20;

Data: 25/09/96;

Imprime prog: ligado;

Variaveis Exogenas Temporais

Precopelxe: Triangular $[2.80,2.5,3.0]$;

Variaveis Exogenas Constantes

Prod equil: Triangular $[30000.0,19200.0,58500.0]$

Custo anozero: Triangular $[81170.0,64670.0,97670.0]$,

Custo-equil: Triangular $[27160.0,20400.0,32760.0]$,

Custo_fixo: Spike[18959.0];

Variaveis Endogenas Temporais

Producao;

Variaveis Endogenas Constantes

Producao atual,

Custo unitario total;

Resultados [TIR: $3: 0.20$, VA: $3: 33000, \mathrm{RBC}: 3: 1.5, \mathrm{PBS}: 3: 3, \mathrm{PBE}: 3: 3, \mathrm{CTA}: 3: 60000$, Custo_unitario_total:3:0.5]; 


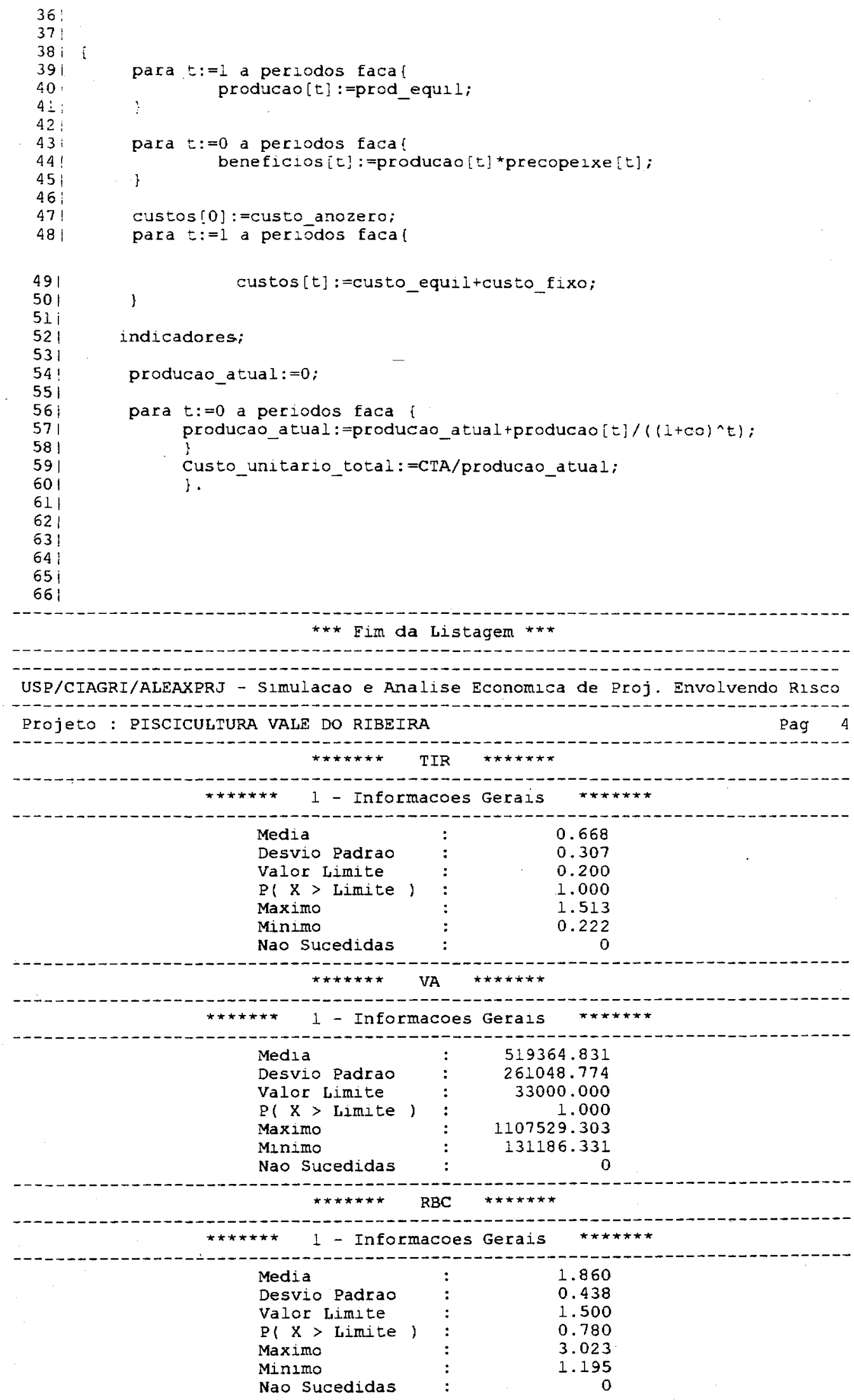




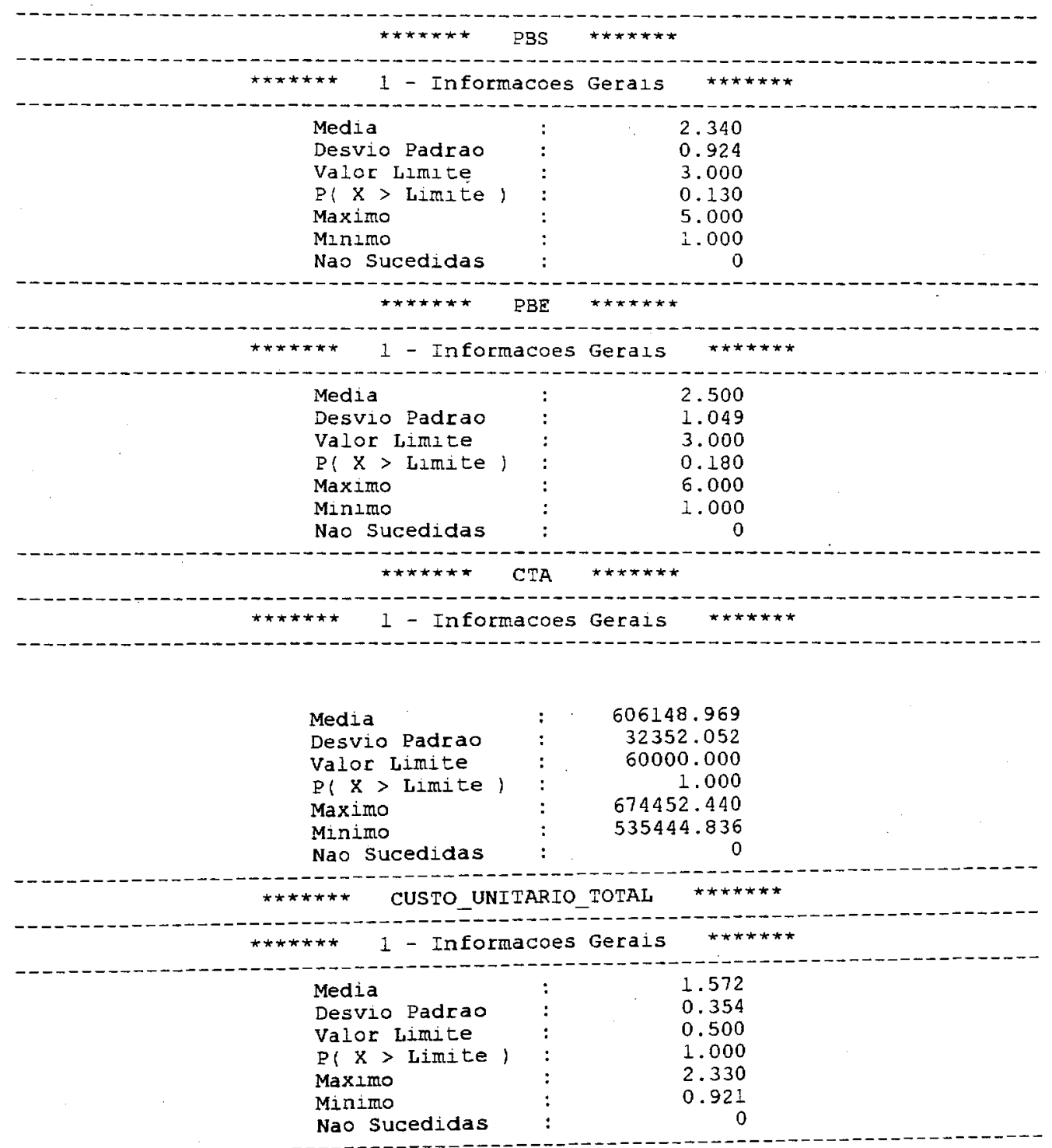




\section{UNIVERSIDADE DE SAO PAULO}

\section{I A G R I - Centro de Informatica na Agricultura}

Sistema de Analise de Projetos em Condicoes Deterministas -- Versao 1.0 --

Dados Gerais Sobre o Projeto

Nome do Projeto : ANALISE DE INVESTIMENTO EM PISCICULTURA

Analista : LUIS HENRIQUE ANDIA

Nome do Arquivo : PEIXEPP9.PRJ Data : 25.09.96

Custo de Oportunidade : $9.00 \%$

Indicadores de Rentabilidade do Projeto

Valor Atual

Taxa Interna de Retorno ...

Relacao Beneficio/Custo ...

Payback Simples ..........

Payback Economico ........

Custos Totais Atualizados..
263675.35

46.92 \%

1.52

3.00 periodo(s)

3.00 periodo(s)

503122.49 


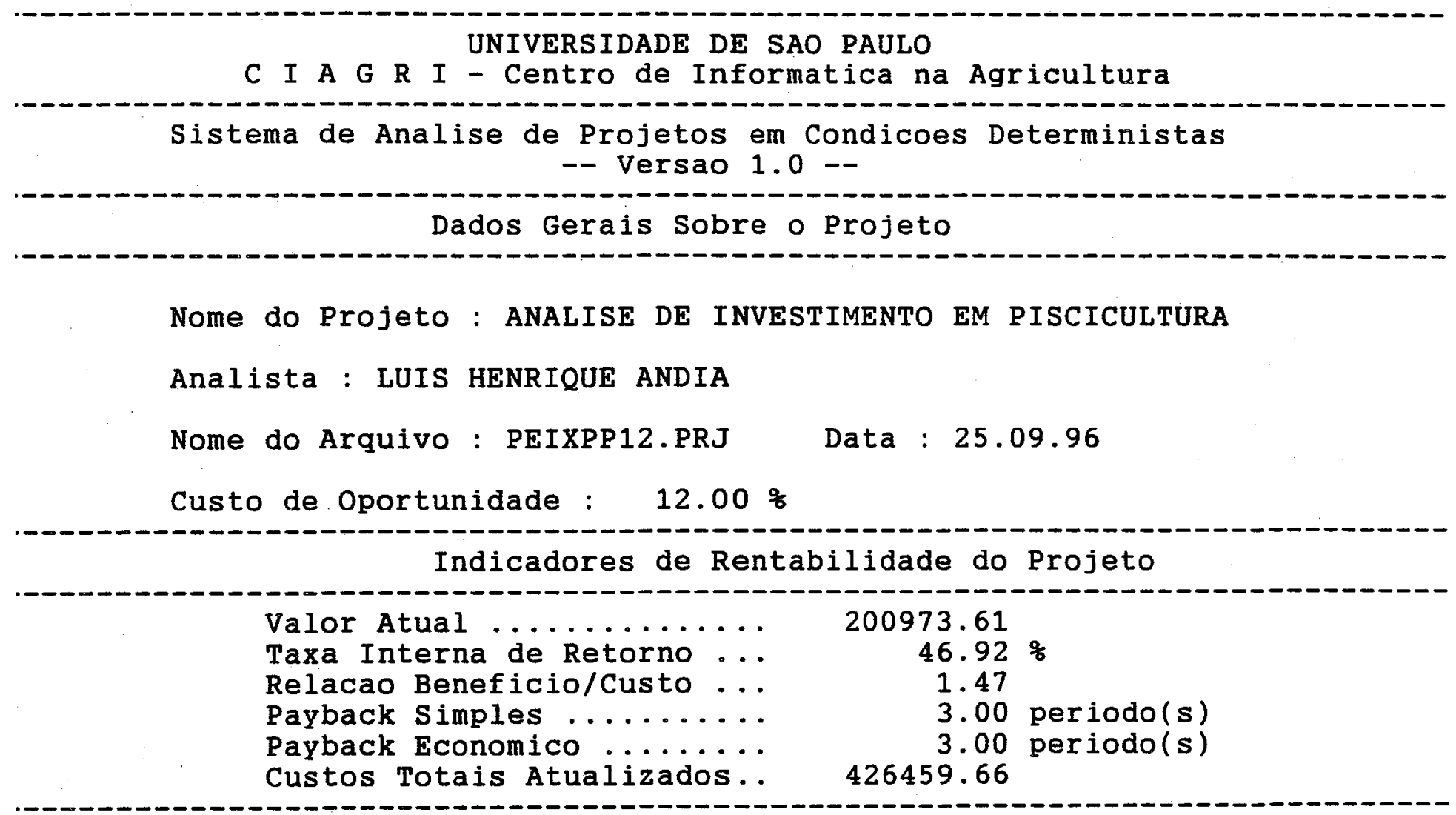




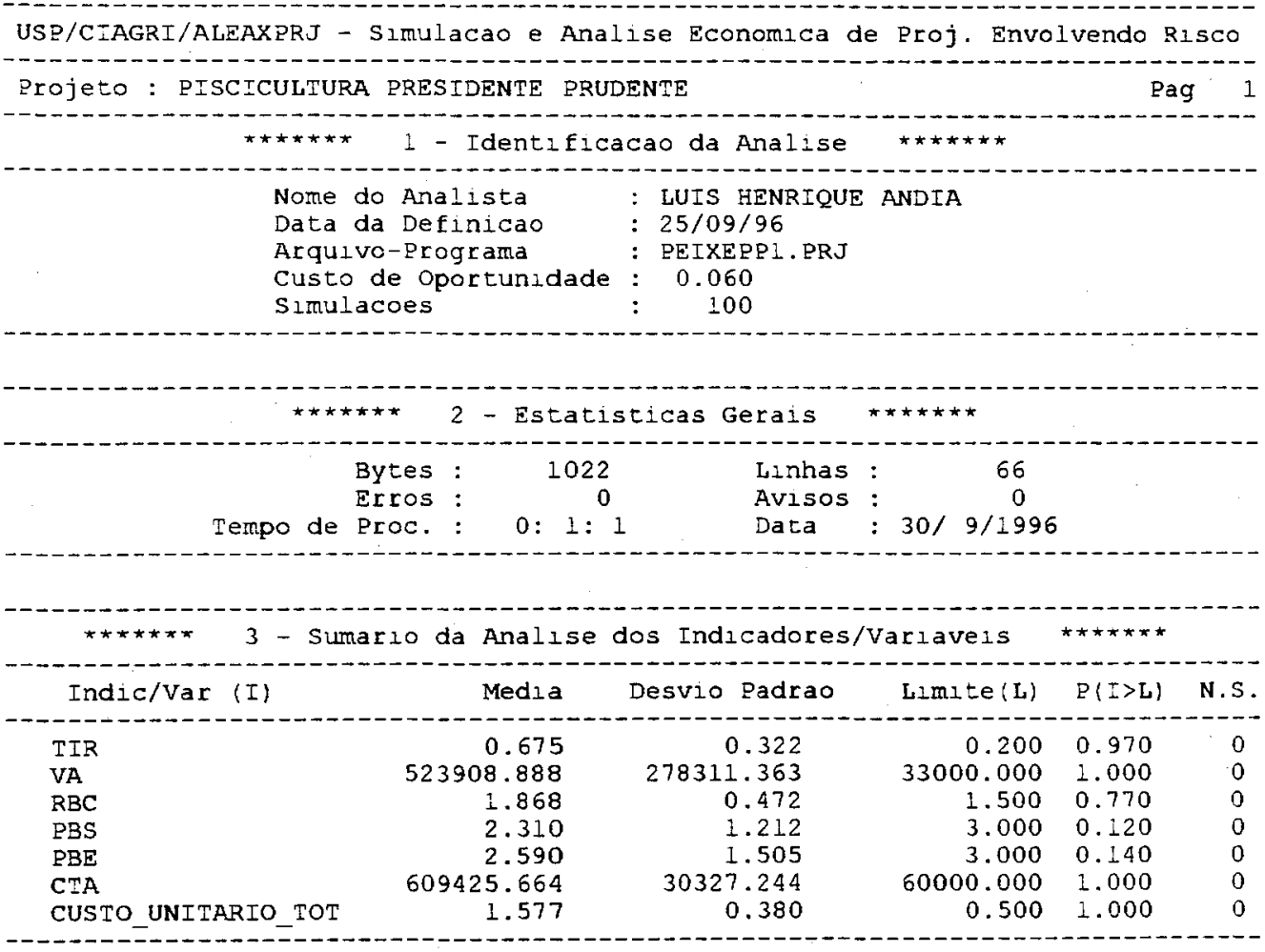

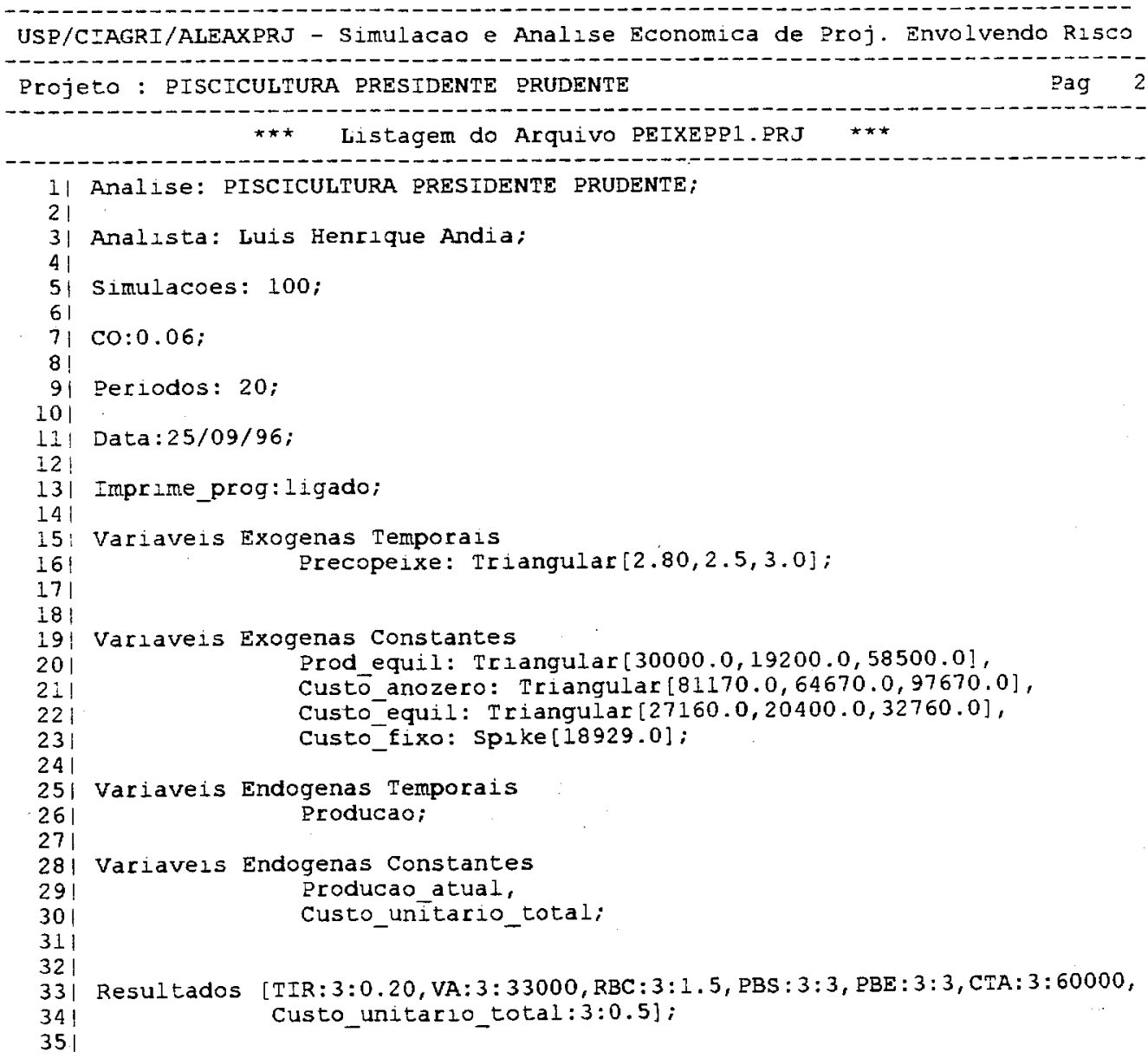




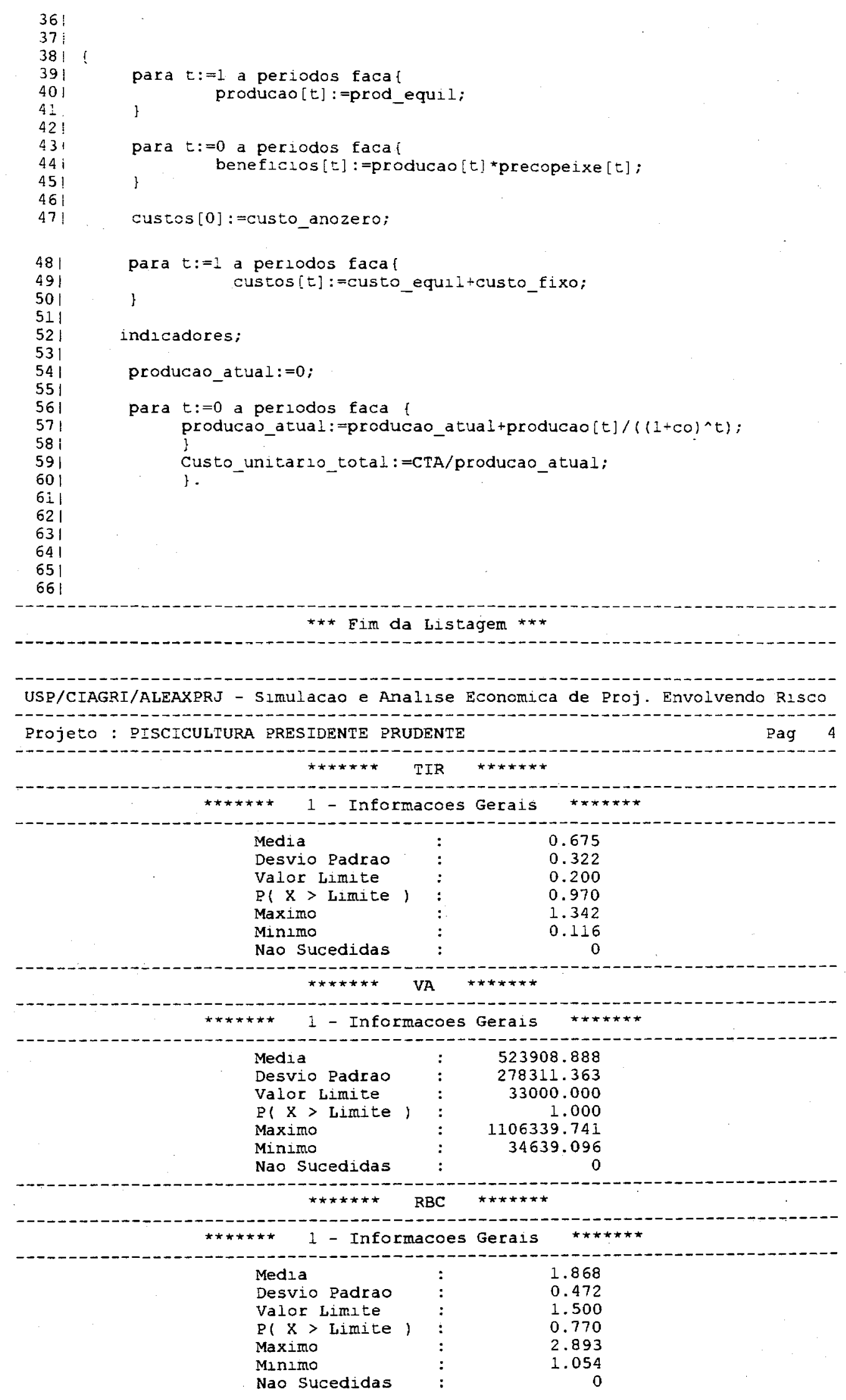




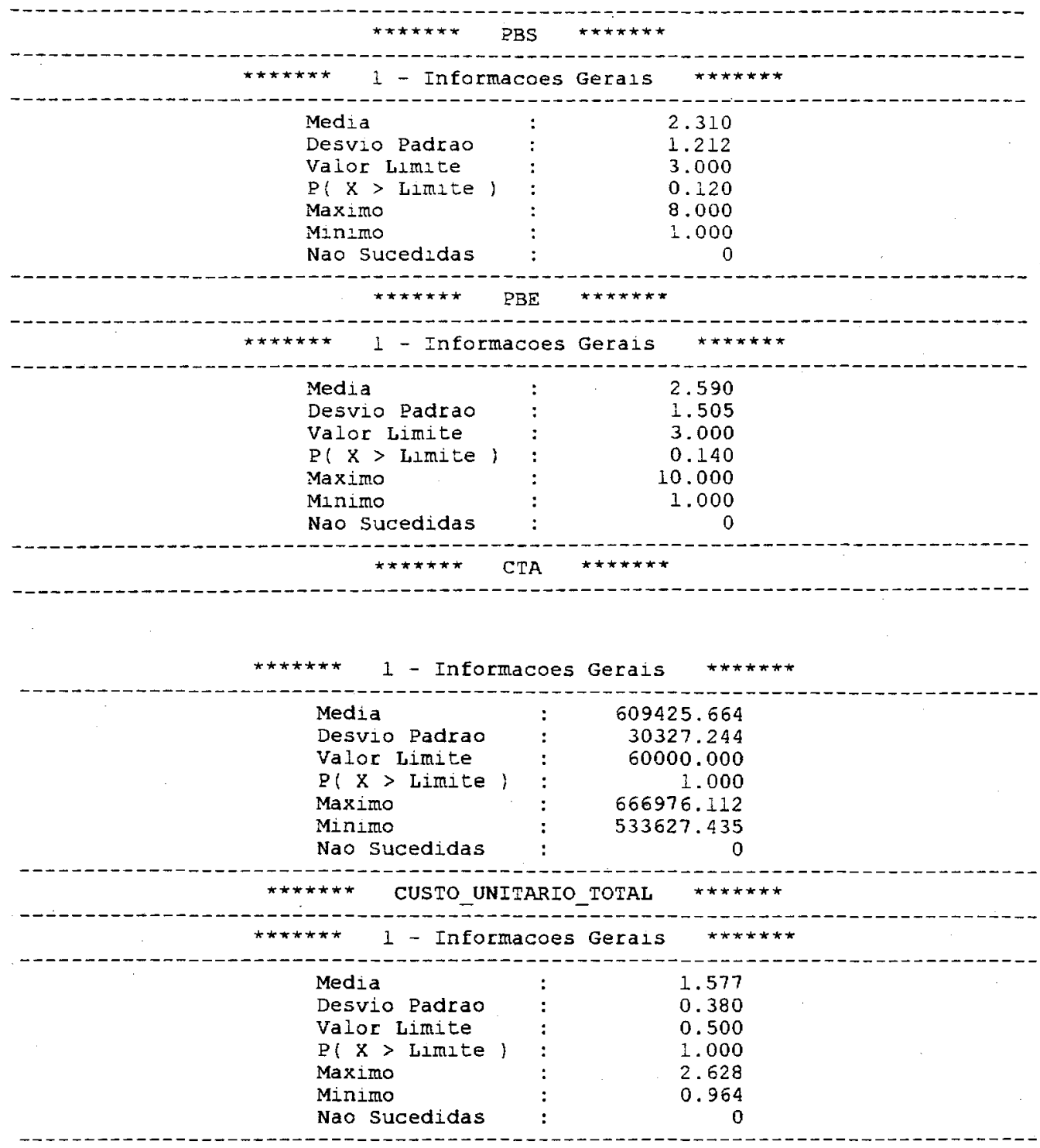

